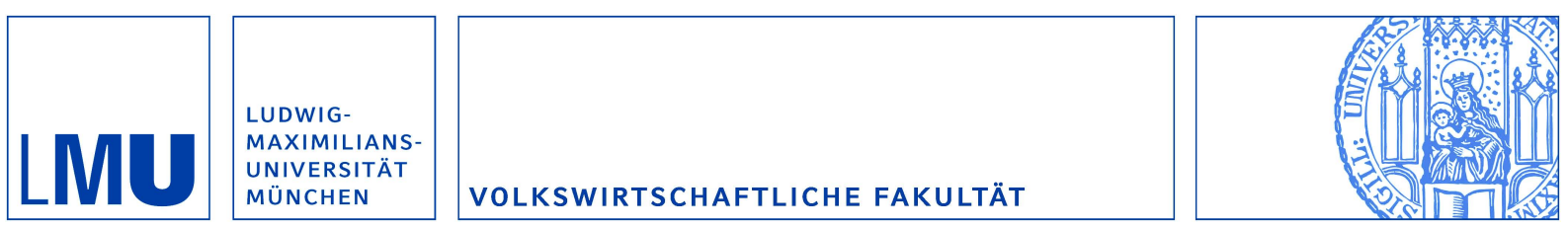

Buchheim, Lukas und Link, Sebastian:

The Effect of Disaggregate Information on the Expectation Formation of Firms

Munich Discussion Paper No. 2017-15

Department of Economics

University of Munich

Volkswirtschaftliche Fakultät

Ludwig-Maximilians-Universitä† München

Online at https://doi.org/10.5282/ubm/epub.41214 


\title{
The Effect of Disaggregate Information on the Expectation Formation of Firms
}

\author{
Lukas Buchheim Sebastian Link*
}

\begin{abstract}
November 9, 2017
This paper studies a new aspect of firms' expectation formation by asking whether expectations primarily reflect aggregate, industry-wide information (e.g., industry trends) or disaggregate information (e.g., firm-specific information). First, we show that disaggregate information is strongly associated with expectations even when controlling for aggregate information at high-dimensional industry levels. Moreover, aggregate and disaggregate information explain comparable shares of the variance in expectations. Second, we exploit a natural experiment to identify the causal effect of new information on expectations. The predictable demand effects for durable goods due to the German VAT increase of 2007 implied that, at the time, durable goods retailers had access to more reliable information about their future demand than non-durable goods retailers. Utilizing this observation in a difference-in-differences design, we find that "treated" firms were significantly more forward-looking ahead of the VAT-induced demand shifts. Overall, our results suggest that firms rationally incorporate disagreggate information into their expectations.
\end{abstract}

Keywords: Expectation Formation, Firm Behavior, Survey Data, Natural Experiments in Macroeconomics, Heterogeneity in Expectations

JEL Classification: D84, D22, E20, E32, E65

\footnotetext{
*Department of Economics, LMU Munich, Schackstraße 4, 80539 Munich, Germany; Lukas Buchheim: lukas.buchheim@econ.lmu.de; Sebastian Link: sebastian.link@econ.lmu.de. For helpful comments we thank Theresa Kuchler, Johannes Stroebel, Uwe Sunde, Michael Weber, Joachim Winter, and Basit Zafar as well as participants at the SMYE 2016 in Lisbon, of the annual meeting of the VfS 2016 in Augsburg, the annual congress of the EEA 2016 in Geneva, the IFO Conference on Macroeconomics and Survey Data 2016 in Munich, the Labor Workshop 2017 in Landeck, the CRC 190 Retreats 2017 in Berlin and Munich, and seminar participants at LMU Munich and the IFO Institute. We also thank Heike Mittelmeier and Shuyao Yang from the IFO Institute for help with the data. Lukas Buchheim gratefully acknowledges financial support from the German Research Foundation (DFG) through CRC TR 190, and Sebastian Link gratefully acknowledges financial support from the Egon-Sohmen-Graduate-Center at the Munich Graduate School of Economics and funding from the DFG through GRK 1928.
} 


\section{Introduction}

The expectations of firms regarding their own future business conditions are an important determinant of their investment, hiring, and pricing decisions. Yet, empirically little is known about which types of information are incorporated in these expectations. Firms gather their information from diverse sources such as news articles, market sentiment, their order books, or their own market research. Put in more abstract terms, firms may rely on both aggregate, industry-wide information (public industry benchmarks, market sentiment, the component of private signals that is correlated across firms) and disaggregate information (the component of private or sub-industry level information that is uncorrelated with aggregate information) when forming their expectations. ${ }^{1}$

This paper contributes to the literature by inquiring how important aggregate and, in particular, disaggregate information are for the expectation formation of firms. We address the following two questions:

1. To which extent is disaggregate information reflected in the expectations of firms?

2. What is the causal effect of news about a disaggregate demand shock on expectations?

Answering these questions is challenging, because it requires micro data on both firms' expectations as well as proxies for their information sets. We circumvent this constraint by exploiting the panel dimension of the IFO Business Survey (IBS). This survey is unique in asking a sample of around 7000 firms that is representative for the German economy about both their current and their expected business conditions at monthly frequency. The panel structure of the data allows us to directly and precisely account for aggregate information via time fixed effects.

Measuring disaggregate information is more demanding. Our methodological contribution is the observation that, in a panel regression framework, the future realized business conditions of firms can serve as a proxy for disaggregate information. The idea is that, by the Frisch-Waugh-Lovell Theorem, the industry-specific time fixed effects employed in the panel regressions flexibly filter out aggregate industry-level information and realizations. As a result, the residual variation in the future business conditions reflects a firm-specific expectation error as well as those components of the firms' information sets that are uncorrelated with aggregate information at the industry level. It directly follows from this argument that the future realized business conditions of firms are a valid proxy for disaggregate information.

Our answer to the first question is that disaggregate information is an important component of the expectations of firms. Across all empirical specifications, there is a strong association between expectations and future business conditions, the proxy for disaggregate information. The main

\footnotetext{
${ }^{1} \mathrm{~A}$ number of recent papers argues that the distinction between aggregate and disaggregate information is important for understanding macroeconomic dynamics. On the one hand, a focus on aggregate information may be optimal if it helps firms to coordinate (Hellwig and Veldkamp, 2009) or when it can be acquired and processed more cheaply than disaggregate information (Veldkamp and Wolfers, 2007). On the other hand, putting a lower weight on disaggregate (private) information and focusing on aggregate information may fuel animal spirits and amplify or cause news-driven business cycles (e.g., Angeletos and La'O 2013; Beaudry and Portier, 2014, provide a survey of the literature).
} 
specification thereby controls for the aggregate component of firms' information at the fairly narrow two-digit industry level (e.g., manufacture of furniture) of the German industry classification. ${ }^{2}$ Since firms' privately observed signals (e.g., their order books) are typically highly correlated within those narrow sub-sectors, the strong association between disaggregate information and expectations in this context is particularly noteworthy.

Additional analyses reveal that the expectations, which cover a six month window, are more strongly associated with disaggregate information about the near future (one quarter ahead) than with information about the more distant future (two quarters ahead). We also compare the extent to which aggregate and disaggregate information are successful in explaining variation in expectations both via the marginal $R^{2}$ of the measures for information and a Shapley variance decomposition. As one might expect, the share of variance explained by disaggregate information is lowest in industries with arguably the strongest aggregate component in business conditions (services and manufacturing) and highest in industries with a weak aggregate component (retail and wholesale). Independent of the particular industry, the analyses show that aggregate and disaggregate information are roughly equally important for explaining variation in expectations.

To address the second question concerning the causal effect of new information on expectations, we exploit a natural experiment that arose in the context of the three percentage point increase in the German VAT in January 2007. Specifically, the prospect of rising prices after the VAT increase led to highly predictable demand effects for durable goods, as manifested in a spike in demand before January 2007 and a strong demand reversal thereafter. In contrast, the demand for non-durable goods was largely unaffected by the change in the VAT. ${ }^{3}$ Hence, ahead of the VAT increase, durable goods retailers had access to more reliable information about future demand than non-durable goods retailers. While the quality of available information about future demand around the time of the VAT increase was thus higher for durable than for non-durable retailers, the business conditions and expectations of all retail firms follow similar trends at all other times. We exploit this similarity of durable and non-durable retailers in a difference-in-differences design to identify the causal effect of the VAT-induced temporary increase in the quality of information on expectations.

The main finding here is that the treated durable goods retailers become more forward-looking once the demand shock enters the expectation window and, hence, information of higher quality is available to them. The effect is quantitatively large; the weight of disaggregate information in explaining expectations increases by a factor two. The increased weight of disaggregate information in expectations is entirely driven by the disaggregate information about the more distant future,

${ }^{2}$ The WZ 03 classification of the German Statistical Office (Klassifikation der Wirtschaftszweige 2003) used in this paper largely corresponds to NACE Rev. 1.1 (the European Industry Classification System). The WZ 03 two-digit codes (divisions) are, in general, more narrow than the NAICS (North American Industry Classification System) two-digit codes (sectors). Often, WZ 03 two-digit divisions are comparable to NAICS three-digit subsectors (NAICS version of 2002); for example, in manufacturing there are 23 WZ 03 two-digit divisions, 3 NAICS twodigit sectors, and 21 NAICS three-digit subsectors. In total, there are 60 WZ 03 two-digit divisions and 20 (103) NAICS two-digit (three-digit) sectors (subsectors).

${ }^{3}$ D'Acunto, Hoang, and Weber (2016) document a sizable increase in consumers' readiness to spend on durable goods in response to the expected price increase due to the VAT change. 
possibly reflecting the fact that information about the VAT-induced demand shock was available from early on.

This paper is the first to document the causal effect of new information on the expectations of firms in a real world setting. Identifying this effect is challenging because the information sets of firms are typically unobservable and data on the expectations of firms is scarce. The VAT-induced demand shock in Germany is thus a rare natural experiment for which both changes in firms' information sets can be inferred and high frequency data on expectations exists. By showing that firms become more forward-looking when new (and reliable) information becomes available, this paper complements recent work by Coibion, Gorodnichenko, and Kumar (2015) who demonstrate by means of survey experiments that firms rationally adjust their expectations in response to additional information. ${ }^{4}$

This paper contributes to the study of the determinants of firms' expectations by showing that disaggregate and aggregate information are equally important drivers of expectations. Taking a similar perspective as this paper but focusing on one specific type of aggregate information, Fuhrer (2015) shows that the expectations of firms are informed by the consensus of past forecasters. Fuhrer's and our findings regarding the determinants of expectations thus complement the literature on survey expectations of professional forecasters and firms that tests specific models of expectation formation by inquiring whether relevant information is neglected in the expectations (see Pesaran and Weale, 2006, for a literature review). For example, Coibion and Gorodnichenko (2012, 2015), Andrade and Le Bihan (2013), and Dovern, Fritsche, Loungani, and Tamirisa (2015) test the implication of models of sticky information (Mankiw and Reis, 2002) and rational inattention (Sims, 2003; Woodford, 2003; Maćkowiak and Wiederholt, 2009, 2015) that expectations react sluggishly to shocks. Similarly, Bacchetta, Mertens, and Van Wincoop (2009), Gennaioli, Ma, and Shleifer (2015), and Massenot and Pettinicchi (forthcoming) test - and reject - the implication of rational expectations that forecast errors are uncorrelated with past observables. ${ }^{5}$

While work on the determinants of firms' expectations is rather scarce, a number of recent papers is concerned with the determinants of consumer expectations. D'Acunto, Hoang, and Weber (2016) study the adjustment of consumers' inflation expectations to the German VAT shock of 2007 and the ensuing effects on the willingness to purchase durable goods. There is also an increasing number of works that examine the impact of past personal experiences on expectations (e.g., Ehrmann and Tzamourani, 2012; Malmendier and Nagel, 2016; Kuchler and Zafar, 2015) or the adjustment of consumer expectations to new information in survey experiments (e.g., Armantier, Nelson, Topa, van der Klaauw, and Zafar, 2016; Cavallo, Cruces, and Perez-Truglia, 2017; Armona, Fuster, and

\footnotetext{
${ }^{4}$ In parallel work with the IBS data, Triebs and Tumlinson (2016) use the German reunification in 1990 as a natural experiment. They show that it took firms from the former East German states between two and five years to learn forecasting their business situation within the new capitalist environment they faced after 1990.

${ }^{5}$ Another strand of the literature evaluates the forecasting properties of survey expectations. Recent examples of this line of work are Ang, Bekaert, and Wei (2007) and Faust and Wright (2013), who show that inflation expectations are among the best available predictors of realized inflation. In contrast, Greenwood and Shleifer (2014) find a strong negative correlation between investors' expectations of stock market returns and the realized returns. In classical work, König, Nerlove, and Oudiz (1981) and Nerlove (1983) show strong bivariate associations between different outcome variables (prices, business conditions) and the corresponding expectations.
} 
Zafar, 2016).

The knowledge about the degree to which aggregate and disaggregate information influence expectations may contribute to a better understanding of macroeconomic dynamics in several ways. Veldkamp and Wolfers (2007) argue that the distinction between aggregate and disaggregate information is important for understanding the extent of synchronized price movements, which amplify the business-cycle co-movement across sectors. Similarly, learning about disaggregate shocks to large individual firms can help anticipate business cycle movements if these shocks cause nonnegligible general equilibrium effects because firms are "granular" in the sense of Gabaix (2011). Finally, our results suggest that disaggregate information is a time-varying source of cross-sectional heterogeneity in expectations, which, in turn, exhibits stable correlations with the fluctuations of aggregate variables (e.g., Mankiw, Reis, and Wolfers, 2004; Bachmann, Elstner, and Sims, 2013; Ben-David, Graham, and Harvey, 2013; Bachmann, Elstner, and Hristov, 2017). As such, this paper complements the works by Ito (1990), Patton and Timmermann (2010), and Bachmann and Elstner (2015) who demonstrate that time-constant differences in firms' optimism and pessimism as well as persistent differences in priors are important drivers of cross-sectional disagreement.

The next section describes the survey data of the IBS used in this paper. Section 3 develops the conceptual framework to dissect the impact of disaggregate and aggregate information on expectations. Section 4 utilizes this framework in panel regressions to quantify the effect of both types of information in general. In Section 5, we exploit the natural experiment given by the German VAT increase in 2007 to estimate the causal effect of new information on expectations. The last section concludes.

\section{Data}

The main data source of this paper is the IFO Business Survey (IBS). This data contains survey information at the firm level that is elicited monthly. The IBS is primarily used to construct the IFO Business Climate Index, Germany's most important lead indicator of economic activity (see Becker and Wohlrabe, 2008, for details on the survey). The IBS is divided into four industry surveys that cover the main sectors of the economy (manufacturing, services, retail/wholesale, construction), with each encompassing a sample of more than thousand firms representative for the German economy. Due to methodological peculiarities of the construction survey, our analysis focuses on data from the manufacturing (IBS-IND, 2015), services (IBS-SERV, 2015), and retail/wholesale (IBS-TRA, 2015) surveys.

The main data of interest are the responses of firms to questions regarding their realized and expected general business conditions. Specifically, every month all firms in the sample of the IBS are asked to provide an assessment of their current realized business conditions, which can be either bad (encoded as -1), normal (0), or good (1). Using a similar three point scale, the IBS also elicits firms' expected business conditions for an expectation window of six months. ${ }^{6}$ According to our

\footnotetext{
${ }^{6}$ Given that our main analysis rests on linear econometric models, quantitative data would be preferable to the qualitative data of the IBS. However, quantitative data on firms' expectations of comparable sectoral depth and
} 
interpretation, the categorical variables on the general business conditions and expectations of firms are informed by the same latent variable that is likely related to their profitability. Bolstering this interpretation, Link (2017) reports that the sector aggregates of business conditions and expectations from the IBS closely follow the log deviation from trend of sector-specific aggregate revenue. ${ }^{7}$ Similarly, Abberger, Birnbrich, and Seiler (2009) find, in a meta survey of the retail/wholesale sample, that firms mostly refer to their current and expected profits and sales when they answer the questions of the IBS.

Our sample consists of all firms in the micro data of the IBS between March 2005 and October 2015 that remain in the sample for at least one year. The latter restriction is needed, because most of the empirical models include reported business conditions for the past six months (including the current month) and the following six months. For the same reason, the first month of the sample, March 2005, is the sixth month after the launch of the survey of the service sector in October 2004. Accordingly, our sample ends in October 2015 as, at the time of writing, the micro data were available until April 2016. The sample is large, comprising of, on average, 2400 manufacturing firms, 2170 service firms, and 1330 retailers/wholesalers per month. We harmonize the data over time and across the industry surveys following Link (2017). This primarily involves assigning the industry code of the official German industry classification system (Klassifikation der Wirtschaftszweige 2003, abbreviated as WZ 03, which closely follows the European industry classification NACE Rev. 1.1) to each firm based on the internal industry classification system of the IFO Institute. We also collapse the product-level surveys conducted in the retail/wholesale sector prior to 2006 to the firm level.

Sample attrition is low. Table 7 in Appendix A shows that roughly 90 percent of firms remain in the sample after one year, with the number of firms declining by five to six percentage points

long time horizon, which is required for the analyses of this paper, is unavailable. Given these data constraints, we carefully verify that employing linear models delivers reliable results. The application of the Frisch-Waugh-Lovell Theorem in Section 4.1 shows that the data is consistent with the symmetry assumption imposed by linear models. Appendix B.1 performs the main panel analyses from Section 4.2 on binarized versions of the categorial data using both linear panel models and fixed effect logit estimators. The marginal effects estimated via both types of models are nearly identical, showing that the categorial nature of the data should be of little concern.

${ }^{7}$ The exact wording of the question regarding the realized business conditions of firms is as follows: "Current situation: We evaluate our current business condition (latest business trends) as [1] good, [0] satisfactory (typical for the season), [-1] bad." In turn, the question regarding expectations is: "Expectations for the next six months: After elimination of purely seasonal fluctuations the development of our business will be [1] more favorable, [0] about the same, [-1] more unfavorable." Hence, the wording of the question regarding expectations seemingly seeks to elicit the expected change in business conditions. This would be inconsistent with the interpretation that both categorical survey responses are informed by the same latent variable. However, Link (2017) documents several facts that favor our interpretation. First, aggregate expectations lead aggregate conditions by several months in each sector-specific survey, while the correlation between aggregate expectations and aggregate changes in business conditions over the past six months is highest at contemporaneity. Second, there is a positive association between current business conditions and expectations in the micro data, consistent with both variables referring to the same persistent latent variable. If expectations were referring to changes in business conditions, in contrast, one would expect mean reversion, and, hence, a negative association between current conditions and expectations. Third, a horse race between both interpretations in the micro data clearly favors both variables being driven by the same latent variable. Last, but not least, the data is mainly used for the calculation of the IFO Business Climate Index, which is a weighted average of the elicited business conditions and expectations. Taking the average of these two variables is most sensible if they represent the same latent variable. The practitioners at the IFO Institute agreed with this interpretation in private conversations. 
Table 1: Transition Frequencies

\begin{tabular}{lc|ccc|ccc}
\hline & & \multicolumn{3}{|c|}{ Conditions Next Period } & \multicolumn{3}{c}{ Expectations Next Period } \\
\hline & & 1 & 0 & -1 & 1 & 0 & -1 \\
\hline Current & 1 & 0.233 & 0.064 & 0.003 & 0.130 & 0.074 & 0.007 \\
Conditions/ & 0 & 0.064 & 0.410 & 0.045 & 0.071 & 0.481 & 0.062 \\
Expectations & -1 & 0.003 & 0.046 & 0.133 & 0.009 & 0.060 & 0.106 \\
\hline & Sum & 0.300 & 0.520 & 0.181 & 0.210 & 0.615 & 0.175 \\
\hline
\end{tabular}

Notes: This table shows the transition frequencies of reported realized business conditions and expected business conditions. The left (right) panel shows the frequencies of reported business conditions (expected business conditions) in the next reported month for each possible current report of business conditions/expectations. Since these statistics are derived from the time dimension of the panel dataset, the overall frequencies of reported future conditions/expectations displayed in the last row (Sum) are equal to the overall frequencies for the current conditions/expectations, which are, for this reason, omitted.

per year thereafter. The average spell length of firms in our sample is more than five years. Firms also have a high response rate: they answer the survey in more than three out of four months. ${ }^{8}$ We linearly interpolate missing observations if the answers are missing for at most two consecutive months.

The empirical analyses of this paper seek to explain the variation in expectations about firms' future business conditions with variation in future realized business conditions. Table 1 displays the time variation of both variables by reporting the aggregate transition frequencies between the categorical values of both the realized (left panel) and expected business conditions (right panel) from one month to the next. ${ }^{9}$ The table shows that reported business condition change frequently. The business conditions differ between the current and next month in between two and three out of ten months, regardless of whether they currently report bad, normal, or good conditions. The conditional transition frequencies of expectations are almost identical if current expectations equal zero and are slightly higher - one change in reported expectations in four out of ten months - when expectations are either good or bad. This results in a slightly lower fraction of normal realized conditions vis-a-vis normal expectations (0.52 vs. 0.61), possibly reflecting the shorter reporting window of realized conditions than the expectation window (one month vs. six months). Considering that firms report different realized or expected business conditions in at least two out of ten months but remain in the sample for more than five years on average, there is hence considerable (within firm) variation both in the dependent and the independent variables of interest.

\footnotetext{
${ }^{8}$ Across industry surveys, the average sample spell and response rates are as follows: manufacturing: 6.3 years and 81 percent; services: 5.4 years and 75 percent; retail/wholesale: 5.3 years and 81 percent.

${ }^{9}$ The transition frequencies within each of the three industry surveys are similar to the aggregate, as Table 8 in Appendix A shows.
} 


\section{Expectations and Disaggregate Information: Conceptual Framework and Empirical Model}

This section presents a conceptual framework that establishes how, using panel data, future realized business conditions can be used as a proxy for disaggregate information.

\subsection{Conceptual Framework}

Denote firm $i$ 's realized business condition at time $t$ by $y_{i, t}$ and note that realized business conditions can be decomposed into an aggregate component $a_{t}$ and a disaggregate component $d_{i, t}$. Hence, $y_{i, t}=a_{t}+d_{i, t}$, with $d_{i, t}$ uncorrelated with $a_{t}$. We assume that the future aggregate and disaggregate business conditions at $t+1, a_{t+1}$ and $d_{i, t+1}$, both consist of known, uncorrelated components denoted by $\hat{a}_{t}^{t+1}$ and $\hat{d}_{i, t}^{t+1}$, and unknown shocks denoted by $\alpha_{t+1}$ and $\delta_{i, t+1}$, respectively. We call $\hat{a}_{t}^{t+1}$ aggregate information, and $\hat{d}_{i, t}^{t+1}$ disaggregate information; $\alpha_{t+1}$ and $\delta_{i, t+1}$ are normal, independent and zero mean shocks with variances $\sigma_{\alpha}^{2}$ and $\sigma_{\delta}^{2} \cdot{ }^{10}$ Given the information known at $t$, the expected business conditions at $t+1$ are hence given by $E_{t}\left[y_{i, t}\right]=E_{t}\left[a_{t+1}\right]+E_{t}\left[d_{i, t+1}\right]=\hat{a}_{t}^{t+1}+\hat{d}_{i, t}^{t+1}$.

When reporting their expectations in $t$, firms use their information as embodied in $\hat{a}_{t}^{t+1}$ and $\hat{d}_{i, t}^{t+1}$, but also make an error $\varepsilon_{i, t}$ that has a zero mean and is uncorrelated with the shocks $\left(\alpha_{t+1}, \delta_{i, t+1}\right)$. Firm $i$ 's observed expectations $\hat{y}_{i, t}^{t+1}$ are hence given by

$$
\hat{y}_{i, t}^{t+1}=\hat{a}_{t}^{t+1}+\hat{d}_{i, t}^{t+1}+\varepsilon_{i, t}
$$

The challenge for assessing the importance of aggregate and disaggregate information for expectation formation is that the information sets $\left(\hat{a}_{t}^{t+1}, \hat{d}_{i, t}^{t+1}\right)$ are, in general, unobservable. Our empirical strategy is based on two ideas to overcome this constraint. First, with panel data it is possible to non-parametrically account for the aggregate information $\hat{a}_{t}^{t+1}$ via time fixed effects. Second, given this and the information structure, future firm-specific realized business conditions serve as a proxy for the disaggregate information.

To see these points, consider the following empirical model that regresses expectations at $t, \hat{y}_{i, t}^{t+1}$, on date fixed effects $\psi_{t}$ and future realizations $y_{i, t+1}$ :

$$
\hat{y}_{i, t}^{t+1}=\psi_{t}+\beta_{1} y_{i, t+1}+\epsilon_{i, t} .
$$

\footnotetext{
${ }^{10}$ We think of the aggregate and disaggregate components of business realizations, information, and shocks as the within-time decompositions of these variables into a common and an idiosyncratic component. Given this, the aggregate and disaggregate components of the variables are uncorrelated by construction. Regarding the knowledge of firm $i$ given by $\hat{a}_{t}^{t+1}$ and $\hat{d}_{i, t}^{t+1}$, we are agnostic about whether firms know the entire learnable information (as implied by, e.g., models of rational expectations), or only subsets of it (as implied, e.g., by models of rational inattention). This is, because this paper is concerned with identifying the sources of information that govern the expectations of firms and not with their forecast precision or their forecast errors. Nevertheless, we implicitly impose a minimum level of rationality by assuming that the unknown shocks $\alpha_{t+1}$ and $\delta_{i, t+1}$ have zero mean. This is innocuous, since the empirical specification accounts for consistent deviations from this assumption via firm fixed effects.
} 
By the Frisch-Waugh-Lovell Theorem, $\beta_{1}$ can also be identified via

$$
\hat{\nu}_{i, t}=\beta_{1} \nu_{i, t}+\eta_{i, t}
$$

Here, $\hat{\nu}_{i t}$ and $\nu_{i t}$ are the residuals of regressing expectations and future realizations, respectively, on date fixed effects

$$
\begin{aligned}
\hat{y}_{i, t}^{t+1} & =\hat{\lambda}_{t}+\hat{\nu}_{i, t} \\
y_{i, t+1} & =\lambda_{t}+\nu_{i, t} .
\end{aligned}
$$

Given the definition of observed expectations in (1) and because $\hat{a}_{t}^{t+1}$ and $\hat{d}_{i, t}^{t+1}+\varepsilon_{i, t}$ are uncorrelated, it holds that $\hat{\lambda}_{t} \stackrel{p}{\rightarrow} \hat{a}_{t}^{t+1}$ and, hence, $\hat{\nu}_{i t}, \stackrel{p}{\rightarrow} \hat{d}_{i, t}^{t+1}+\varepsilon_{i, t}$. By a similar argument, it holds that $\nu_{i, t} \stackrel{p}{\rightarrow} d_{i, t+1}=\hat{d}_{i, t}^{t+1}+\delta_{i, t+1}$. Hence, (3) becomes equivalent to

$$
\hat{d}_{i, t}^{t+1}=\beta_{1}\left(\hat{d}_{i, t}^{t+1}+\delta_{i, t+1}\right)+\left(\eta_{i, t}-\varepsilon_{i, t}\right) .
$$

After controlling for time fixed effects, future firm-specific realized business conditions are thus a proxy for disaggregate information $\hat{d}_{i, t}^{t+1}$, albeit with classical measurement error given by the disaggregate shock $\delta_{i, t+1}$. As a consequence, the coefficient of future realizations will reflect attenuation bias. Specifically, since the true coefficient of regressing $\hat{d}_{i, t}^{t+1}$ on itself equals one, we have that $\beta_{1} \rightarrow 1 \times \operatorname{Var}\left(\hat{d}_{i, t}^{t+1}\right) /\left(\operatorname{Var}\left(\hat{d}_{i, t}^{t+1}\right)+\sigma_{\delta}^{2}\right)$, where the latter term is the attenuation factor.

This analysis delivers three important observations. First, with panel data it is possible to use future firm-specific business conditions as a proxy for disaggregate information. This is because time fixed effects non-parametrically filter out both aggregate information $\hat{a}_{t}^{t+1}$ and aggregate business conditions $a_{t+1}$ when applying the Frisch-Waugh-Lovell Theorem. Second, the size of the coefficient of the future realized business conditions can be interpreted as a measure of how well informed firms are about their future (disaggregate) business conditions. Ceteris paribus, firms are better informed about their disaggregate business conditions if the variance of the disaggregate shock $\sigma_{\delta}$ decreases. This leads to an increase in the attenuation factor $\operatorname{Var}\left(\hat{d}_{i, t}^{t+1}\right) /\left(\operatorname{Var}\left(\hat{d}_{i, t}^{t+1}\right)+\sigma_{\delta}^{2}\right)$ and hence to an increase in $\beta_{1}{ }^{11}$ Third, due to the attenuation bias, the marginal $R^{2}$ of using future realized conditions as a proxy for disaggregate information is a lower bound of the variance explained by disaggregate information $\hat{d}_{i, t}^{t+1}$.

\subsection{Empirical Model}

The empirical model that guides the empirical analyses throughout the paper follows directly from the conceptual framework outlined above. Specifically, we estimate a slightly modified version of (2) to test whether expectations primarily reflect aggregate information at the industry level or

\footnotetext{
${ }^{11}$ While the inclusion of an additional regressor into (3) alters the definition of the attenuation factor, the conclusion that a decrease in $\sigma_{\delta}$ implies an increase in $\beta_{1}$ remains valid as long as the disaggregate shock $\delta_{i, t}$ is uncorrelated with the additional regressor.
} 
disaggregate information orthogonal to industry-specific information. The empirical model is the following:

Expectations $_{i, t}^{+6 m}=\beta_{1}$ Conditions $_{i,(t+1, t+6)}+\beta_{2}$ Conditions $_{i,(t, t-5)}+m_{i}+a_{t} \times \mathbb{1}\left(\right.$ Subsector $\left._{i}\right)+\varepsilon_{i, t}$.

As for the conceptual framework (2), the dependent variable of the empirical model (4) are firm $i$ 's expectations stated at month $t$, which cover an expectation window of six months. As in (2), moreover, we non-parametrically identify the aggregate information at the two-digit level of the German industry classification system of 2003, which is roughly equivalent to three-digit NAICS subsectors (see Footnote 2), via the subsector-specific time fixed effects $a_{t} \times \mathbb{1}\left(\right.$ Subsector $\left._{i}\right){ }^{12}$ Furthermore, we proxy for disaggregate information via the future realizations of business conditions during the expectation window of the following six months, as given by Conditions ${ }_{i,(t+1, t+6)}$. Conditions C $_{i,(t+1, t+6)}$ is calculated as the moving average of the reported business conditions between the months $t+1$ and $t+6$.

We slightly modify the conceptual framework (2) by including firm fixed effects $m_{i}$ and the six month moving average of current and past realized business conditions, Conditions ${ }_{i,(t, t-5)}$, as additional independent variables. The firm fixed effects $m_{i}$ filter out a constant firm-specific tendency of expectations that may be caused by structural factors like an (un)successful business model as well as persistent firm-specific optimism or pessimism (as documented by Bachmann and Elstner, 2015). The past business conditions control for adaptive expectations or the effect of past (disaggregate) information on expectations. This ensures that the proxy for disaggregate information, Conditions ${ }_{i,(t+1, t+6)}$, predominantly captures the effect of newly relevant information that is not included in past conditions on expectations. That being said, none of our results qualitatively depend on the inclusion of either $m_{i}$ or Conditions ${ }_{i,(t-5, t)}$ in the empirical model.

Finally, note that the empirical model (4) is linear irrespective of the discrete and ordinal nature of the data. This choice is driven by the non-existence of standard methods for the estimation of fixed effects models with non-binary ordinal data. While Riedl and Geishecker (2014) find that linear panel data models generally perform well in comparable settings with large cross-sections and long time series, it is a priori not clear that assuming linearity is appropriate in our context. We therefore verify in Section 4.1 that the linear model is consistent with the variation present in the data. In addition, Appendix B.1 shows that the estimates of (4) with binarized data are identical irrespective of whether they are estimated via OLS or fixed effect logit.

\section{Decomposing Aggregate and Disaggregate Information: Panel Results}

This section documents the strong association between disaggregate information and the expectations of firms. The analysis begins with an application of the Frisch-Waugh-Lovell Theorem

\footnotetext{
${ }^{12}$ For simplicity and clarity, we abuse notation slightly and assign the same letter to different (but related) parameters and variables. For example, in the empirical model (4), $a_{t}$ denotes the time fixed effect, while in the conceptual framework $a_{t}$ denotes the aggregate business conditions. To avoid confusion, parameters will be uniquely defined within the subsections of the paper.
} 
that displays the substantial variation in disaggregate information along the lines of the conceptual framework in the previous section. In addition, the analysis verifies that the linearity imposed by the empirical model (4) is reflected in the data despite its categorical nature. Then, we turn to the direct estimation of the main empirical model (4) and corresponding model variants to quantify the strength and statistical significance of the positive association between the expectations of firms and disaggregate information. Finally, a comparison of the variance in expectations explained by disaggregate and aggregate information reveals that both sources of information influence expectations to a similar degree.

\subsection{Regression Anatomy of the Identifying Variation}

Section 3 argues that the effect of disaggregate information on expectations can be identified via the partial correlation of expectations and future realized business conditions with both variables purged for their aggregates via time fixed effects. We now bring this argument to the data and analyze the empirical correlation between purged current expectations $\hat{\nu}_{i, t}$ and purged future business conditions $\nu_{i, t}$, our proxy for disaggregate information. In the context of the empirical model $(4), \hat{\nu}_{i, t}$ and $\nu_{i, t}$ are thereby defined as the residuals of the following regressions:

$$
\begin{gathered}
\text { Expectations }_{i, t}^{+6 m}=\hat{\beta}_{2} \text { Conditions }_{i,(t, t-5)}+\hat{m}_{i}+\hat{a}_{t} \times \mathbb{1}\left(\text { Subsector }_{i}\right)+\hat{\nu}_{i, t} \\
\text { Conditions }_{i,(t+1, t+6)}=\tilde{\beta}_{2} \text { Conditions }_{i,(t, t-5)}+\tilde{m}_{i}+\tilde{a}_{t} \times \mathbb{1}\left(\text { Subsector }_{i}\right)+\nu_{i, t} .
\end{gathered}
$$

Given this, note that the linear projection of $\hat{\nu}_{i, t}$ on $\nu_{i, t}$ corresponds to the effect of disaggregate information on expectations, because for $\beta_{1}$ from (4) it holds that $\beta_{1}=\operatorname{Cov}\left(\hat{\nu}_{i, t}, \nu_{i, t}\right) / \operatorname{Var}\left(\hat{\nu}_{i, t}\right)$ by the Frisch-Waugh-Lovell Theorem. ${ }^{13}$

The left panels of Figure 1 plot, separately for each sector-wide survey, the purged expectations $\hat{\nu}_{i, t}$ against the proxy for disaggregate information $\nu_{i, t}$. The large dispersion of $\nu_{i, t}$ along the horizontal axis reveals that there is substantial identifying variation in the disaggregate component of the future realized business conditions even after filtering out the aggregate variation at the subsector level. In addition, the regression lines in these figures, the slopes of which are between 0.25 (services) and 0.29 (manufacturing and retail/wholesale), indicate that there is a strong positive association between disaggregate future realizations, the proxy for disaggregate information, and firms' expectations. Yet, this positive association is somewhat masked by the large visible dispersion of $\hat{\nu}_{i, t}$ that is due to the large number of observations (between approximately 180'000 in the retail/wholesale survey and 330'000 in the manufacturing survey).

Next, we rule out that the positive correlation between disaggregate information and expectations is due to outliers or non-linearities - potentially originating from the categorical nature of the dataand verify that the positive and linear association is a general and robust feature of the data. To this end, the right panels of Figure 1 group the purged future conditions $\nu_{i, t}$ by percentiles and

\footnotetext{
${ }^{13}$ Angrist and Pischke (2008) provide a detailed discussion of the theorem and its usefulness for assessing the identifying variation.
} 
Figure 1: Regression Anatomy

Panel A: Manufacturing
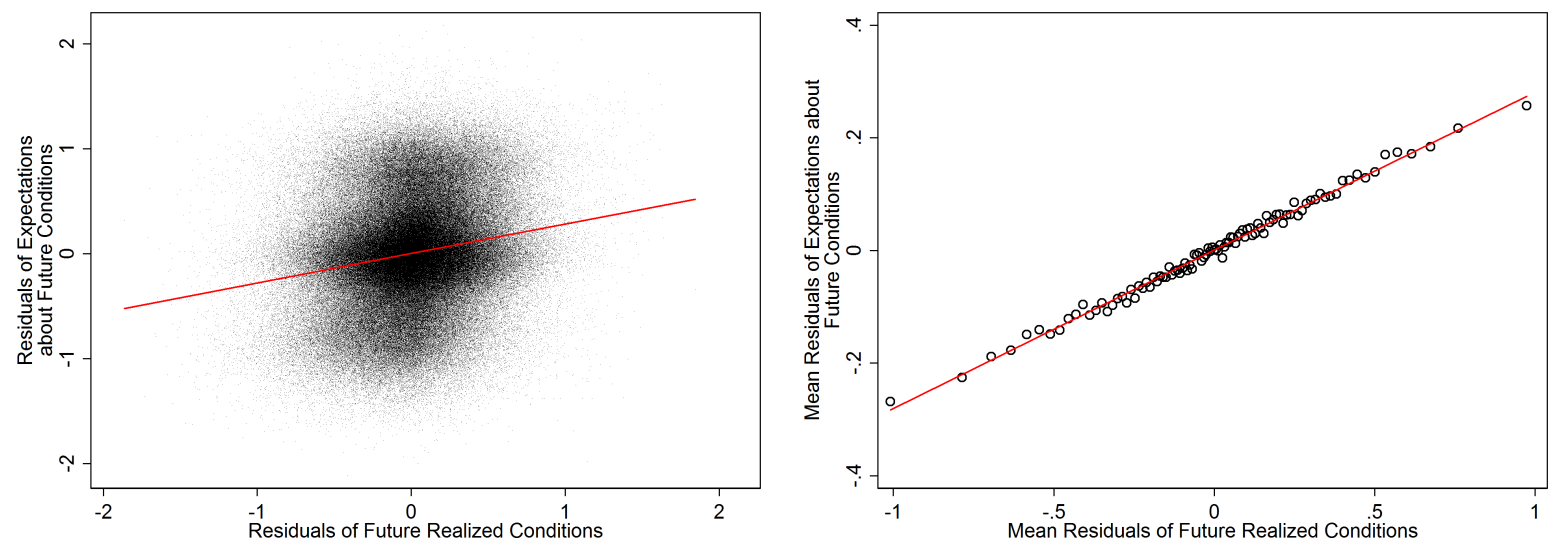

Panel B: Services
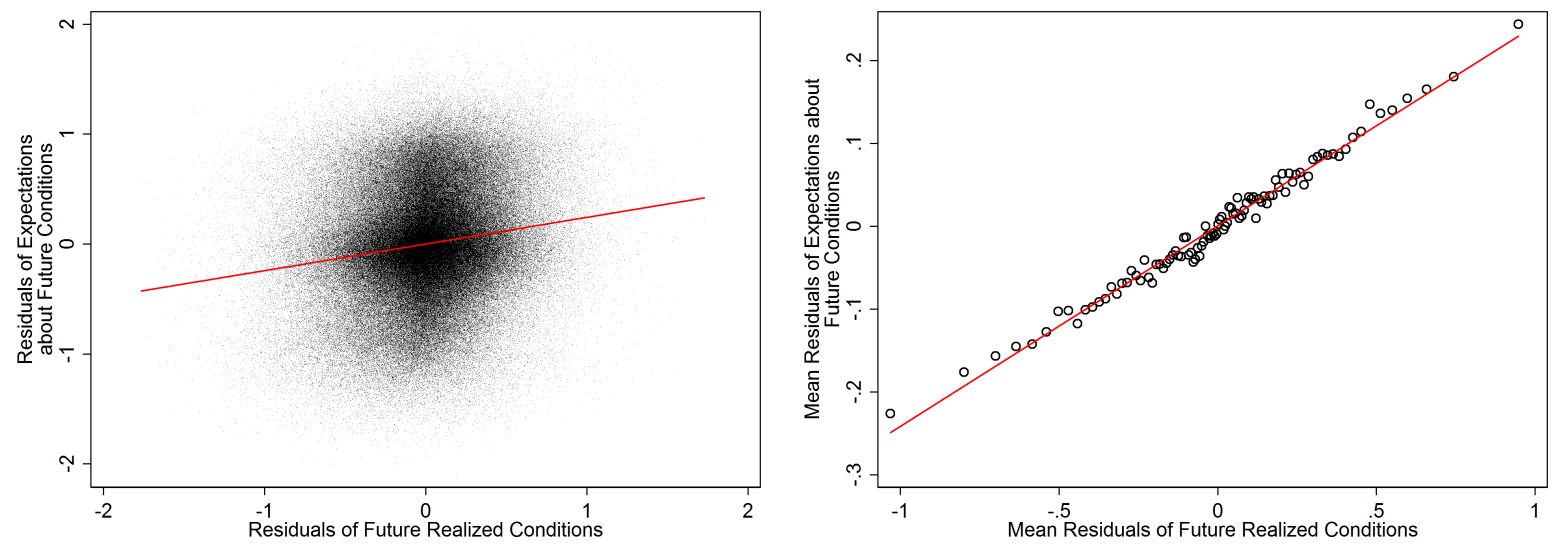

Panel C: Retail and Wholesale
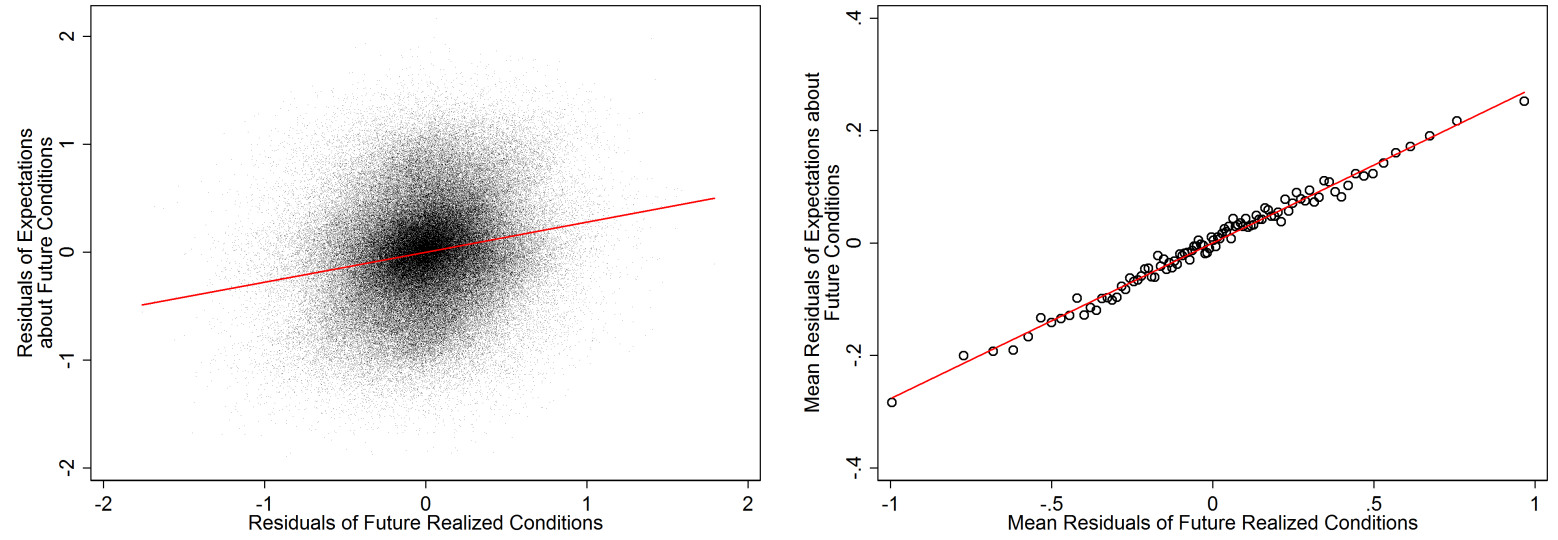

Notes: The left figures plot, for each sector-specific survey of the IBS, firms' six month ahead expectations at $t$ (purged for firm fixed effects and date fixed effects at the two-digit industry level as well as current and past conditions according to (5)) against the future realized business conditions between $t+1$ and $t+6$ (purged for the same variables as expectations according to (6)). The right figures group the residuals of the future conditions by percentile and plot, conditional on the percentile, the means of the purged expectations against the means of the future realized conditions. The straight lines in both panels represent the regressions of purged expectations on purged future conditions. 
plot, conditional on the percentile of $\nu_{i, t}$, the means of the purged expectations $\hat{\nu}_{i, t}$ against the means of the purged future business conditions. Evidently, these conditional means are strongly positively correlated and tightly clustered around the linear projections of $\hat{\nu}_{i, t}$ on $\nu_{i, t}$. The average effect of the proxy for disaggregate information on the expectations of firms is thus constant across the entire domain of disaggregate information, suggesting that the estimation of linear models is appropriate despite the categorical nature of the data.

\subsection{Disaggregate Information Is Strongly Associated with Expectations}

We now proceed to document the main findings of this section. Column (5) of Table 2 reports the estimates of the empirical model (4). As became clear in the regression anatomy exercise, there is a strong positive association between firms' expectations and the future realized business conditions, the proxy for disaggregate information after controlling for aggregate information via time fixed effects. Because the standard deviations of expectations and realized conditions are of similar magnitude, the estimated coefficients imply that a one standard deviation change in realized conditions (disaggregate information) is associated with an adjustment of expectations by between 0.25 (services) and 0.29 (manufacturing and retail/wholesale) of a standard deviation in the same direction. The effects are precisely estimated with standard errors more than one order of magnitude smaller than the point estimates. ${ }^{14}$ Note also that, conditional on future business conditions within the expectation window, expectations seem to exhibit mean reversion with respect to current and past conditions in the manufacturing and service surveys, while they follow current conditions more closely in the retail/wholesale survey.

In Column (5), we non-parametrically control for aggregate information (and aggregate realizations) at the subsector level via the respective high dimensional time fixed effects. For this reason, the coefficient of future realized conditions captures the degree of information about disaggregate outcomes reflected in the expectations. Column (3), in turn, estimates the same coefficient without the time fixed effects. Then, the coefficient reflects the impact of information regarding the firms' total future conditions, i.e., the sum of aggregate and disaggregate conditions, on their expectations. The larger coefficient of future realized conditions in (3) compared to (5) hence indicates, plausibly, that firms expectations reflect the future total conditions more strongly than only the disaggregate conditions. ${ }^{15}$ Finally, the comparison of the results in Columns (3) and (1) reveals that the coefficient of future realized conditions is slightly larger if we remove the firm fixed effects from the set of covariates. This indicates that both expectations and business outcomes are partly determined by firm-specific conditions like, for example, the general success of their business

\footnotetext{
${ }^{14}$ Standard errors are two-way clustered along the firm and time dimensions following Dube, Lester, and Reich (2010) and Cameron, Gelbach, and Miller (2011). This adjusts for serial correlation of standard errors within firms as well as correlations of errors within time periods.

${ }^{15}$ Following the conceptual framework in Section 3.1 and interpreting the coefficient of future conditions as an attenuation factor, the result implies that the ratio of the variance of the aggregate shock $\left(\alpha_{t+1}+\delta_{i, t+1}\right)$ to the variance of aggregate information $\left(\hat{a}_{t}^{t+1}+\hat{d}_{i t}^{t+1}\right)$ is smaller than the ratio of the variance of the disaggregate shock $\delta_{i, t+1}$ to the variance of disaggregate information, $\hat{d}_{i, t}^{t+1}$. While this finding is plausible, it is by no means obvious.
} 
Table 2: Firms' Expectations and Disaggregate Information

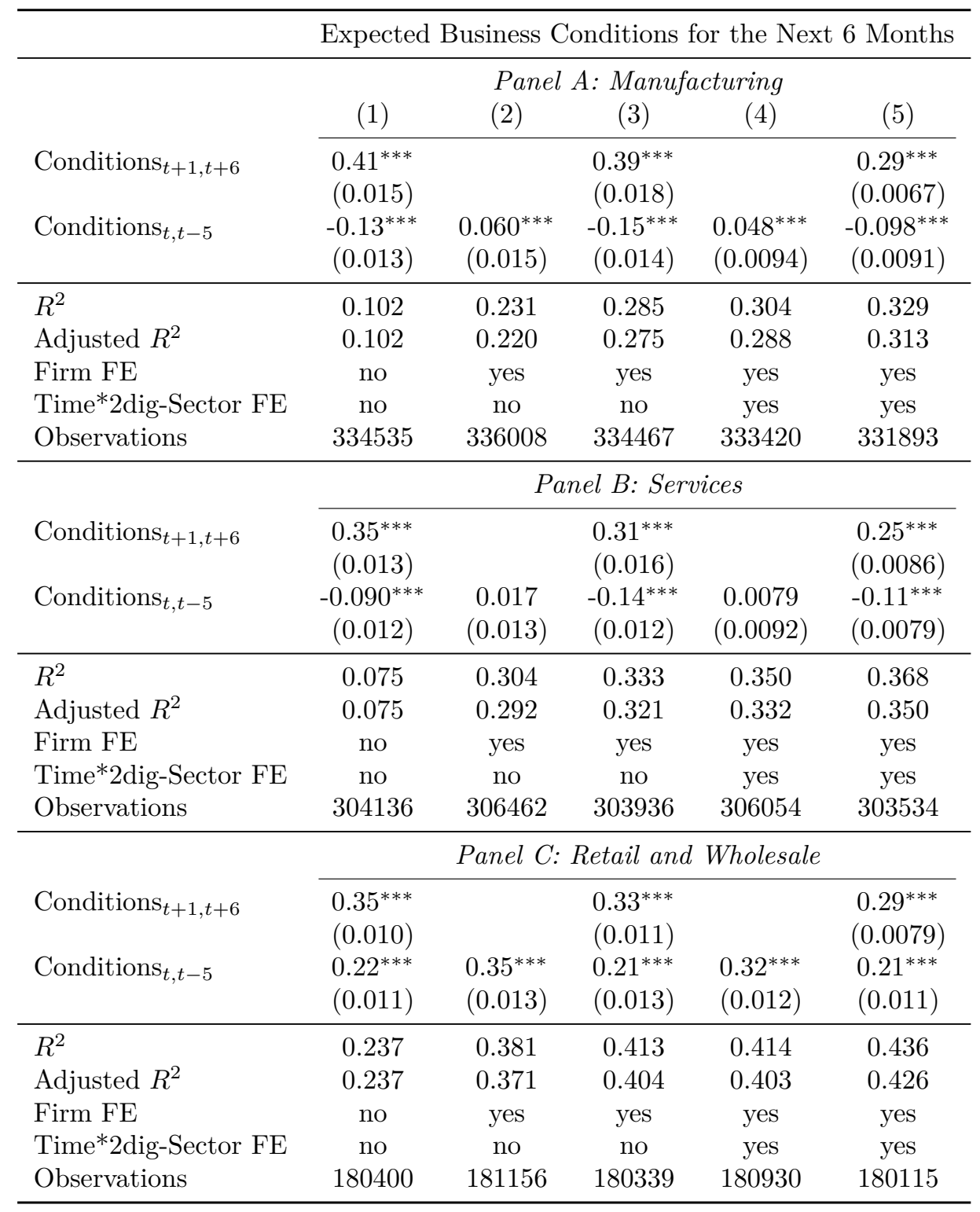

Notes: Conditions $s_{t+1, t+6}$ is the mean of the future realized business conditions in the following six months, which is the proxy for disaggregate information. Conditions ${ }_{t, t-5}$ is defined accordingly. "Time*2dig-Sector FE" are time fixed effects at the two-digit industry level. Standard errors are two-way clustered at the levels of firms and dates. Level of significance: ${ }^{*} p<0.10,{ }^{* *} p<0.05,{ }^{* * *} p<0.01$. 
Table 3: Firms' Expectations and Disaggregate Information for Different Forecast Horizons

\begin{tabular}{lccc}
\hline & \multicolumn{3}{c}{ Expected Business Conditions for the Next 6 Months } \\
\hline & $\begin{array}{c}\text { Panel A: } \\
\text { Manufacturing }\end{array}$ & $\begin{array}{c}\text { Panel B: } \\
\text { Services }\end{array}$ & $\begin{array}{c}\text { Panel } \text { C: } \\
\text { Retail and Wholesale }\end{array}$ \\
\cline { 2 - 4 } Conditions $_{t+4, t+6}$ & $0.11^{* * *}$ & $0.11^{* * *}$ & $0.079^{* * *}$ \\
& $(0.0056)$ & $(0.0062)$ & $(0.0060)$ \\
Conditions $_{t+1, t+3}$ & $0.17^{* * *}$ & $0.15^{* * *}$ & $0.18^{* * *}$ \\
& $(0.0054)$ & $(0.0061)$ & $(0.0053)$ \\
Conditions $_{t, t-2}$ & 0.0055 & $-0.061^{* * *}$ & $0.27^{* * *}$ \\
& $(0.0073)$ & $(0.0077)$ & $(0.0081)$ \\
Conditions $_{t-3, t-5}$ & $-0.11^{* * *}$ & $-0.066^{* * *}$ & $-0.055^{* * *}$ \\
& $(0.0066)$ & $(0.0066)$ & $(0.0068)$ \\
\hline Firm FE & yes & yes & yes \\
Time*2dig-Sector FE & yes & yes & yes \\
$R^{2}$ & 0.332 & 0.370 & 0.449 \\
Adjusted $R^{2}$ & 0.316 & 0.352 & 0.439 \\
Observations & 318098 & 283683 & 172487 \\
\hline
\end{tabular}

Notes: Conditions $s_{t+4, t+6}$ is the mean of the future realized business conditions four to six months into the future. Conditions $s_{t+1, t+3}$, Conditions C $_{t, t-2}$, and Conditions $t_{t-3, t-5}$ are defined accordingly. Conditions C $_{t+1, t+3}$ and Conditions $_{t+4, t+6}$ serve as proxies for disaggregate information. "Time*2dig-Sector FE" are time fixed effects at the two-digit industry level. Standard errors are two-way clustered at the levels of firms and dates. Level of significance: ${ }^{*} p<0.10,{ }^{* *} p<0.05, * * * p<0.01$.

model. ${ }^{16}$

Next, we take a closer look at the time horizon of the disaggregate information reflected in the expectations. To this end, we split the proxy of disaggregate information, the future realized business conditions in the following six months, into business realizations one quarter and two quarters ahead (denoted by Conditions $i_{i,(t+1, t+3)}$ and Conditions ${ }_{i,(t+4, t+6)}$, respectively). For symmetry, we proceed similarly with current and past conditions. The results in Table 3 show that firms' expectations about the following six months are more strongly associated with disaggregate information about the one quarter ahead business conditions than with the conditions two quarters ahead. The difference is less pronounced in the service and manufacturing surveys, where firms potentially face a relatively steady business environment, than in the retail/wholesale survey, where the business environment potentially fluctuates at higher frequency. Overall, the result is consistent with the hypothesis that firms are, in general, better informed about the near than the more distant future.

In Appendix B, we perform various robustness checks all of which leave the results unchanged. Table 10 shows that the parameter estimates are largely independent of the exact specification of the time fixed effects, including the introduction of geographic time fixed effects at the state level. In addition, sample attrition should be of little concern, as the results are identical for subsamples of firms that are observed for sufficiently long time periods. Table 10 also confirms that the expectations of firms are associated with disaggregate information independent of their

\footnotetext{
${ }^{16}$ The remaining results of Table 2 in Columns (2) and (4) will be useful in the analysis of the variance explained in the next subsection.
} 
current business situation. Table 11 demonstrates that the main results are robust to changes in the vector of covariates. For example, we show that controlling for aggregate, industry-wide information by means of (future) industry-level revenues instead of the industry-level fixed effects leads to similar results with coefficients approaching the ones reported in Column (3) of Table 2. This is not surprising, as industry-level revenues plausibly proxy only for parts of the aggregate information available to firms. We also control for lagged expectations or separately for current and past business conditions, with both specifications leading to results very close to the findings reported in this section.

\subsection{Variance Explained by Aggregate and Disaggregate Information}

This section assesses the relative importance of disaggregate information in comparison to aggregate, industry-wide information for explaining variation in the expectations of firms. For this purpose, we first take a look at the marginal $R^{2}$ of these variables. Comparing Columns (2) and (4) of Table 2 shows that the aggregate and industry-level information captured by the time fixed effects add between 3.3 (retail/wholesale) and 7.3 (manufacturing) percentage points to the fraction of overall variance explained. Comparing Columns (4) and (5), the marginal $R^{2}$ of disaggregate information as proxied by the realized future business conditions is between 1.8 (services) and 2.5 (manufacturing) percentage points. Hence, the marginal $R^{2}$ of disaggregate information amounts to between one third (manufacturing) and two thirds (retail/wholesale) of the marginal $R^{2}$ of the aggregate information at the subsector level.

To put these numbers in perspective, recall from the conceptual framework in Section 3.1 that the estimated marginal $R^{2}$ of disaggregate information is a lower bound for its true marginal $R^{2}$. The reason is that the proxy for disaggregate information, the future realized business conditions, induces attenuation bias for the coefficient of disaggregate information. In contrast, the estimated marginal $R^{2}$ of aggregate information closely approximates its true value, because the time fixed effects capture the variance explained by aggregate information flexibly and non-parametrically.

The extent to which proxying for information via future realized conditions leads to underestimating the true marginal $R^{2}$ can be gauged from comparing the marginal $R^{2}$ of the time fixed effects - i.e., the comparison of Columns (2) and (4) — with the marginal $R^{2}$ of realized conditions without time fixed effects - i.e., the comparison of Columns (2) and (3). Without the inclusion of time fixed effects, the realized conditions are a proxy for the sum of disaggregate and aggregate information. Nevertheless, the marginal $R^{2}$ of proxying for both disaggregate and aggregate information is smaller than the marginal $R^{2}$ of flexibly accounting for only the aggregate information via the fixed effects. This suggests that the empirical framework severely underestimates the variance explained by disaggregate information. Seen in this light, the prominent role of disaggregate information in explaining variance in expectations is even more remarkable.

Broadening the perspective, it is also instructive to ask how much of the variance in expectations is explained by the future realized business conditions per se, i.e., when they are not necessarily interpreted as a proxy for (disaggregate) information. The answer to this question is not trivial, 
Table 4: Generalized Shapley Decomposition of the Variance Explained

\begin{tabular}{lccc}
\hline & \multicolumn{3}{c}{ Average Marginal Contribution to $R^{2}$ (in $\%$ of $R^{2}$ ) } \\
\hline & Manufacturing & Services & Retail and Wholesale \\
\cline { 2 - 4 } Conditions $_{t+1, t+6}$ & 16.6 & 10.1 & 21.5 \\
Conditions $_{t, t-5}$ & 3.8 & 3.0 & 17.2 \\
Time*2dig-Sector FE $^{*}$ & 19.4 & 17.7 & 8.3 \\
Firm FE & 60.2 & 69.1 & 53.0 \\
\hline$R^{2}$ & 0.329 & 0.368 & 0.436 \\
Observations & 331893 & 303534 & 180115 \\
\hline
\end{tabular}

Notes: Conditions ${ }_{t+1, t+6}$ is the mean of the future realized business conditions in the following six months. Conditions $s_{t, t-5}$ is defined accordingly. "Time*2dig-Sector FE" are time fixed effects at the two-digit industry level.

as the contribution of the future conditions to the share of total variance explained depends on the order with which the covariates are included in the estimation. This is because the identifying variation of each additional covariate is its partial variation that is uncorrelated with the covariates already included in the model. Clearly, the (partial) identifying variation of each additional covariate declines with the number of covariates already included.

A recent method to deal with this issue is the generalized Shapley value decomposition approach suggested by Shorrocks (2013). ${ }^{17}$ Given groups of covariates defined by the researcher, this method decomposes the overall model $R^{2}$ into the relative contributions of each group. Applied to our setting, the generalized Shapley value corresponds to the average marginal contribution of each group of covariates to the overall model $R^{2}$ across all possible sequences of adding these groups to the empirical model.

We compute the generalized Shapley values for the following four groups of covariates: (A) the realized future business conditions $\left(\right.$ Conditions $\left._{i,(t+1, t+6)}\right)$, (B) the current and past business conditions $\left(\right.$ Conditions $\left._{i,(t, t-5)}\right)$, (C) the set of industry-specific time fixed effects $\left(a_{t} \times \mathbb{1}\left(\right.\right.$ Subsector $\left.\left._{i}\right)\right)$, and (D) the set of firm fixed effects $\left(m_{i}\right) .{ }^{18}$ Table 4 displays the results of this variance decomposition. Evidently, the firm-specific future business conditions and the aggregate information as captured by the time fixed effects both contribute a similar - and sizable - share to the total variance explained. Specifically, the future business conditions contribute, on average, 21.5 percent to the total variance explained in the retail/wholesale survey, and 16.6 and 10.1 percent, respectively, in the manufacturing and services surveys. The aggregate effects at the two-digit industry level contribute, on average, between 8.3 percent (retail/wholesale) and 19.4 percent (manufacturing) to the total variance explained. These statistics are hence consistent with the notion that the

\footnotetext{
${ }^{17}$ Huettner and Sunder (2012) illustrate this approach and review findings of the literature on its desirable properties such as efficiency, monotonicity, and equal treatment of groups as well as of players within groups.

${ }^{18}$ Given this grouping, the generalized Shapley values are computed as follows. Within each of the $4 !=24$ permutations of groups (ABCD, ABDC, ..., DCBA), the respective groups are sequentially added to the regression model and the marginal contribution of each group of covariates to the overall model $R^{2}$ is determined. Each group's Shapley value is then given by the average marginal contribution over all permutations of groups.
} 
manufacturing and services sectors are more exposed to the aggregate business environment than the retail and wholesale sectors. Nevertheless, across all industry surveys, firm-level information as captured by future realized business conditions seems to be an important driver of expectations. ${ }^{19}$

\section{The Effect of New Information on Expectation Formation: Quasi-Experimental Evidence}

The previous section has shown that the expectations of firms reflect information about their future business conditions that is uncorrelated with aggregate or sector-specific fluctuations. As such, firms are at least partially forward-looking when forming their expectations during "normal times." During these periods, however, it is likely that information about future business conditions is relatively imprecise as well as costly to gather and process. In the remainder of the paper, we study an episode during which a subset of firms had reliable and salient information about a disaggregate demand shock and ask how firms incorporate this new information into their expectations.

It is difficult to identify the causal effect of a change in available information on expectations in the field, predominantly because the information sets of firms are unobservable to the researcher. Although aggregate shocks are often observable and can, at times, be anticipated, they affect all firms at the same time so that the effect of new information becomes indistinguishable from the potential impact of other sources of aggregate fluctuations. Hence, it requires knowledge of a disaggregate information shock that affects a well-defined subset of firms to learn more about how expectations react to changes in the quality of available information.

The announcement of the newly formed German government in November 2005 to raise the VAT from 16 percent to 19 percent as of January 2007 constitutes such a disaggregate information shock. ${ }^{20}$ It is well known that a raise in the VAT heterogeneously affects business conditions of retail firms depending on the type of products they sell. While firms trading with durable

\footnotetext{
${ }^{19}$ The decomposition exercise also reveals the very prominent role of time-invariant firm-level factors in explaining variation in the expectations. At least one fifth of the variation in expectations is explained by firm fixed effects which accounts for between 53.0 percent (retail/wholesale) and 69.1 percent (services) of the overall $R^{2}$. The importance of firm fixed effects is not surprising. As shown in Section 2, firms frequently report that they expect normal business conditions. Hence, firm fixed effects close to zero presumably "explain" many of the observations with Expectations ${ }_{i, t}^{+6 m}=0$. In addition, the firm fixed effects also account for the general success of firms' business strategies in the medium and long run as well as for systematic, time-invariant expectation biases (Bachmann and Elstner, 2015, find the latter to be quite prevalent).

${ }^{20}$ During the 2005 election campaign, Ms. Merkel's Christian Democrats (CDU) promised to lower non-wage labor costs and to refinance the decrease in revenue via an increase in the VAT by two percentage points (CDU/CSU, 2005 , p. 13). All other parties with a path to being part of a ruling coalition after the election (Social Democrats, Greens, and Liberals) were in strong opposition to the proposed VAT increase (see, e.g., SPD, 2005, p. 39). As neither the left nor the right blocks (Christian Democrats \& Liberals or Social Democrats \& Greens) gained an absolute majority in parliament (Bundestag), Christian Democrats and Social Democrats formed a "grand coalition" headed by the new chancellor Merkel and decided to increase the VAT by three percentage points in order to consolidate the federal budget; the non-wage labor costs were lowered by one percentage point. The draft of the law was accepted by the federal cabinet on February 22, 2006, and was passed into law by the two chambers of parliament on May 19th (Bundestag) and June 16th (Bundesrat). Given the broad majority of the coalition in both chambers, parliamentary approval of the tax increase did not come as a surprise to the public. D'Acunto, Hoang, and Weber (2016) provide a more detailed discussion and documentation of the unexpectedness and purposes of the 2007 VAT increase.
} 
goods usually face a large anticipation effect in demand resulting in sizable fluctuations of their business conditions, firms trading with non-durable goods are typically not affected. ${ }^{21}$ For the case of the German VAT reform, this asymmetric effect has been documented by D'Acunto, Hoang, and Weber (2016) who find a sizable increase in consumers' readiness to spend on durable goods ahead of the tax rise. Moreover, they do not find evidence for intra-temporal substitution from non-durable to durable goods. Because such anticipation effects in demand are a common result of VAT increases, they were predictable for Germany's durable goods retailers, so that the VAT shock led to a differential treatment regarding the reliability of information about future demand available to durable and non-durable goods retailers.

\subsection{Empirical Strategy: Difference-in-Differences}

We seek to identify the causal effect of the VAT-induced increase in the quality of information on expectations in a difference-in-differences (DiD) design. For this purpose, we assign firms to treatment and control groups based on the findings of Carare and Danninger (2008) and a report of the German central bank (Bundesbank, 2008). Both studies document that the anticiaption effect in demand was strongest in sales of new cars followed by sales of furniture, furnishings, electronic household appliances, and construction material. Accordingly, we assign approximately 220 retailers of cars, furniture, and electronics to the treatment group to which we henceforth refer as "durable goods retailers." The remaining 340 retail firms are assigned to the control group. ${ }^{22}$ As the VAT increase aimed at the consolidation of the federal budget, the policy intervention neither intended to facilitate or suppress sales in specific retail sectors nor was it related to economic conditions in these sectors. The "assignment" of firms to the "treatment" can hence be considered as exogenous.

We further restrict the data set that we use for the analysis of the VAT shock to the expectations of retail firms reported the latest in December 2007 in order to exclude the repercussions of the 2008 financial crisis from the six-month expectation window. In order to be able to observe pre-trends in the expectations and current conditions of sufficient length, we expand the data set to earlier periods covering expectations reported in January 2004 and thereafter. ${ }^{23}$

Figure 2 compares the reported business conditions of the treated firms to aggregate revenues of

\footnotetext{
${ }^{21}$ In Germany, virtually all durable goods are taxed with the full VAT of 19 percent. A sizable fraction of non-durables such as food, newspapers, and flowers are taxed with a reduced rate of 7 percent that has not been changed since 1983.

${ }^{22}$ Specifically, we define firms as being "treated" if they are classified as being part of the following sectors of the German industry classification system of 2003 (WZ 03): "50.1 Sale of motor vehicles," "52.44 Retail sale of furniture, lighting equipment, and household articles," and "52.45 Retail sale of electrical household appliances and radio and television goods" (Destatis, 2003). We do not include firms in the WZ 03 group "52.46 Retail sale of hardware, prints and glass" to the treatment group, as the IBS does not contain such firms at the time of the VAT increase.

${ }^{23}$ The restricted data set hence covers reported business conditions between August 2003 and June 2008 . Another reason for the extension of the data set towards earlier periods is that this raises the number of time periods to 48 , satisfying the rule of thumb from the literature that the number of clusters should not fall far below 50 . In Appendix C.2, we show that the results are virtually the same when using the same start date (March 2005) as in the previous sections.
} 
Figure 2: The VAT-Induced Demand Effects

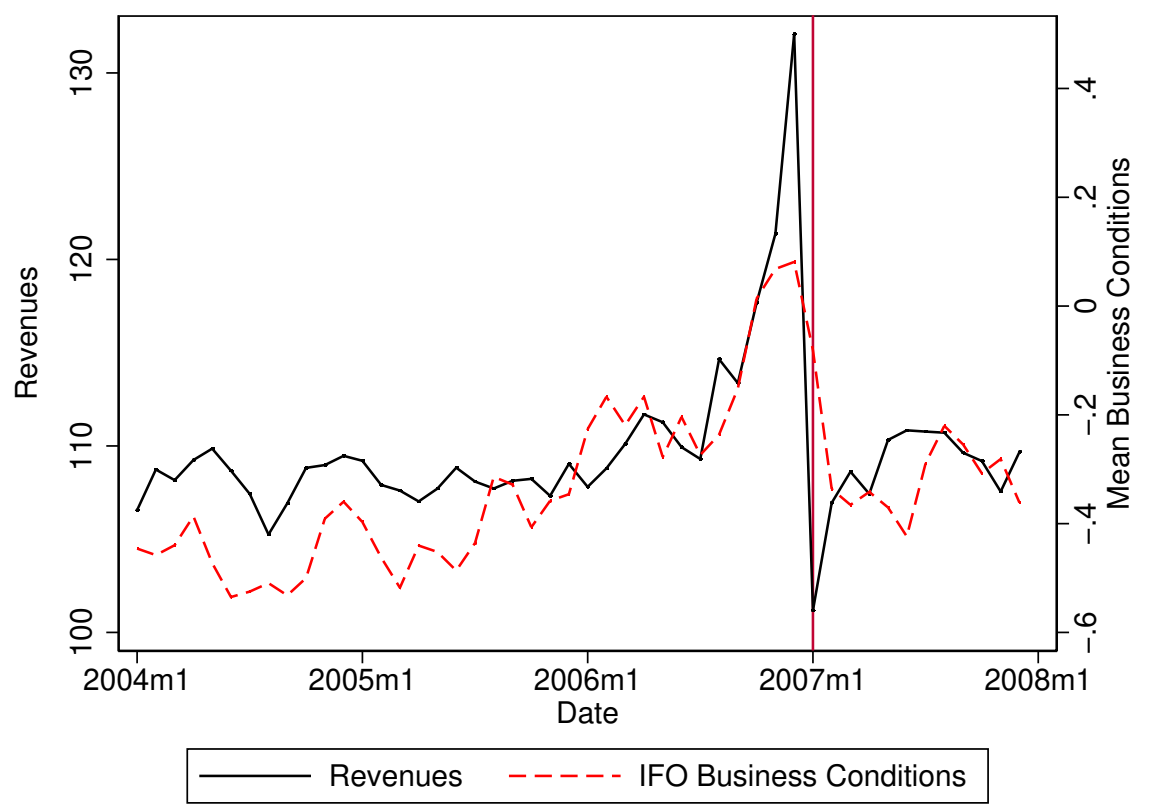

Notes: This figure plots the time series of aggregated revenues in the sectors "treated" by the VAT change (black line) against reported business conditions of the treated firms in the IBS as given by the average responses of retailers of cars, furniture, and electronics (dashed red line). The aggregate revenue series weights the sector-specific revenues by the fraction of treated firms in the respective sectors in the IBS. The vertical red line corresponds to the date of the VAT increase (January 2007).

durable goods retailers. To this end, we construct a measure of aggregate revenue in the treated sectors by weighting the sector-specific revenue series received from the German Statistical Office with the corresponding share of treated firms per sector in the IBS. ${ }^{24}$ Clearly, the assessments of current business conditions in the IBS, although qualitative in nature, closely track aggregate revenues in the corresponding sectors. In particular, both time series display a sharp increase ahead of the VAT change in the beginning of 2007, followed by a sharp downswing in the months thereafter. ${ }^{25}$

The identifying variation exploited in the DiD estimation is the difference in reported business conditions of durable and non-durable goods retailers during the treatment period. Figure 3 illustrates this variation by plotting the business conditions of treated and untreated firms that are purged for the past business conditions and firm fixed effects. ${ }^{26}$ Evidently, the purged current busi-

\footnotetext{
${ }^{24}$ The revenue data are available from the German Federal Statistical Office as monthly time-series at the industry level according to the more recent German industry classification system of 2008 (WZ 08), which largely corresponds to the European classification NACE Rev. 2. The displayed time series in Figure 2 is calculated using the revenue time series of the WZ 08 sectors "45.1 Sale of cars," "47.54 Retail trade with electronic household appliances," and "47.59 Retail trade with furniture" weighted by the fraction of treated firms in the respective sectors observed in the IBS.

${ }^{25}$ Figure 5 in Appendix C.1 plots revenues and average reports of current business conditions in the retail industries unaffected by the VAT change.

${ }^{26}$ Specifically, Figure 3 plots the residuals of the following linear model, averaged separately for treated and untreated firms: Conditions $i, t=\tilde{\beta}_{2}$ Conditions $_{i,(t-1, t-6)}+\tilde{m}_{i}+\tilde{\nu}_{i, t}$.
} 
Figure 3: Identifying Variation in Business Conditions

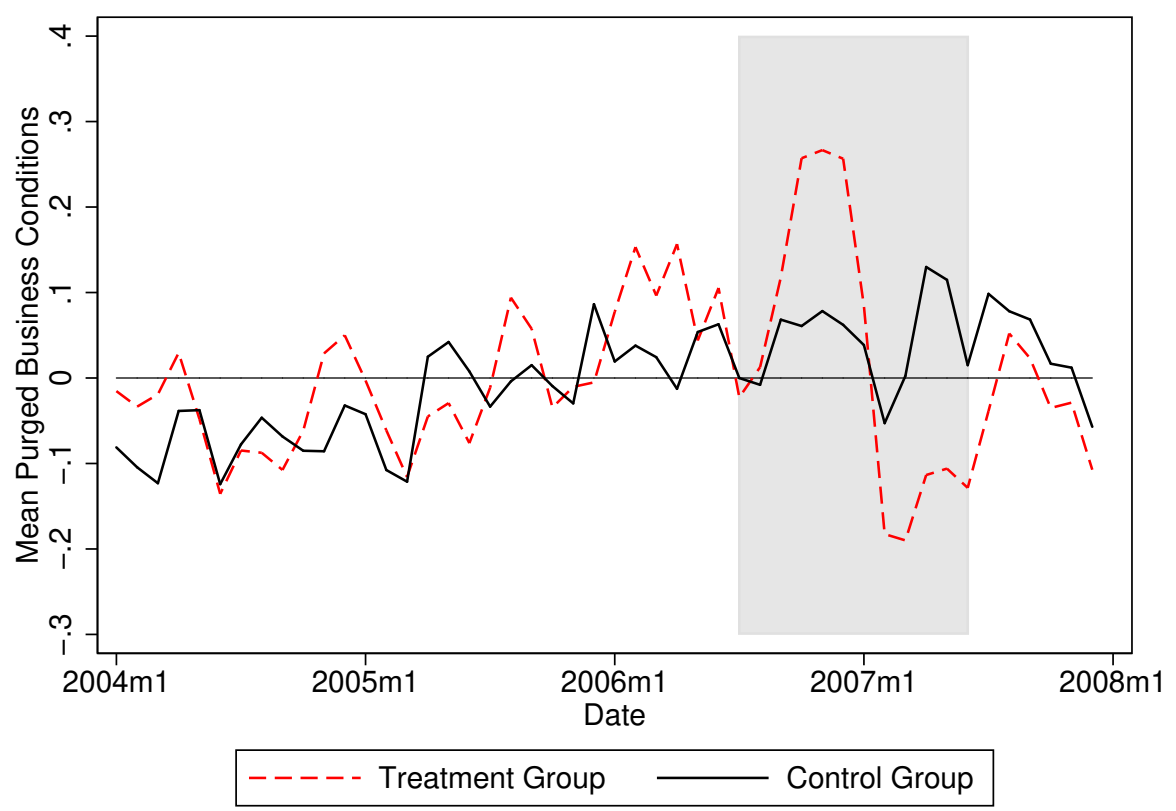

Notes: The dashed red line plots the mean of business conditions reported by the treated firms (durable goods retailers), purged for past conditions and firm fixed effects. The solid black line plots the same variable for the firms in the control group (all other retail firms). The shaded area corresponds to the treatment period between July 2006 and June 2007.

ness conditions of the treated and untreated firms follow similar trends with the notable exception of the treatment period defined as the six months before and after the VAT increase on January 1st, 2007. During this period, the business conditions of the treated firms are highly non-linear. Due to the overall similarity of all retail firms, non-durable goods retailers, which were not affected by the VAT increase, seem to be a well-suited control group that can be used to filter out aggregate trends and different sources of shocks during the treatment period.

Next, we show that the expectations of treated and control firms follow a common trend when the VAT-induced demand shock is outside of the expectation window - the key assumption for the identification of causal effects in a DiD design. To inspect the common trend in expectations, we purge the expectations firms for their current conditions and past trends as well as time-invariant firm characteristics captured by firm fixed effects, as before. ${ }^{27}$ Figure 4 plots the mean purged expectations separately for durable goods retailers and all other retail firms. Clearly, the expectations do not differ substantially between both groups before the end of 2005. If anything, the expectations of treated firms already start appreciating in November 2005. Interestingly, this perfectly coincides with the announcement of the VAT increase. Hence, the common trend assumption is very likely to hold.

We exploit the similarity of the durable and non-durable retail firms to study the adjustment of

$\overline{27}$ These purged expectations correspond to the residuals of the following regression: Expectations ${ }_{i, t}^{+6 m}=$ $\hat{\beta}_{2}$ Conditions $_{i,(t, t-5)}+\hat{m}_{i}+\hat{\nu}_{i, t}$. 
Figure 4: Common Trend in Expectations

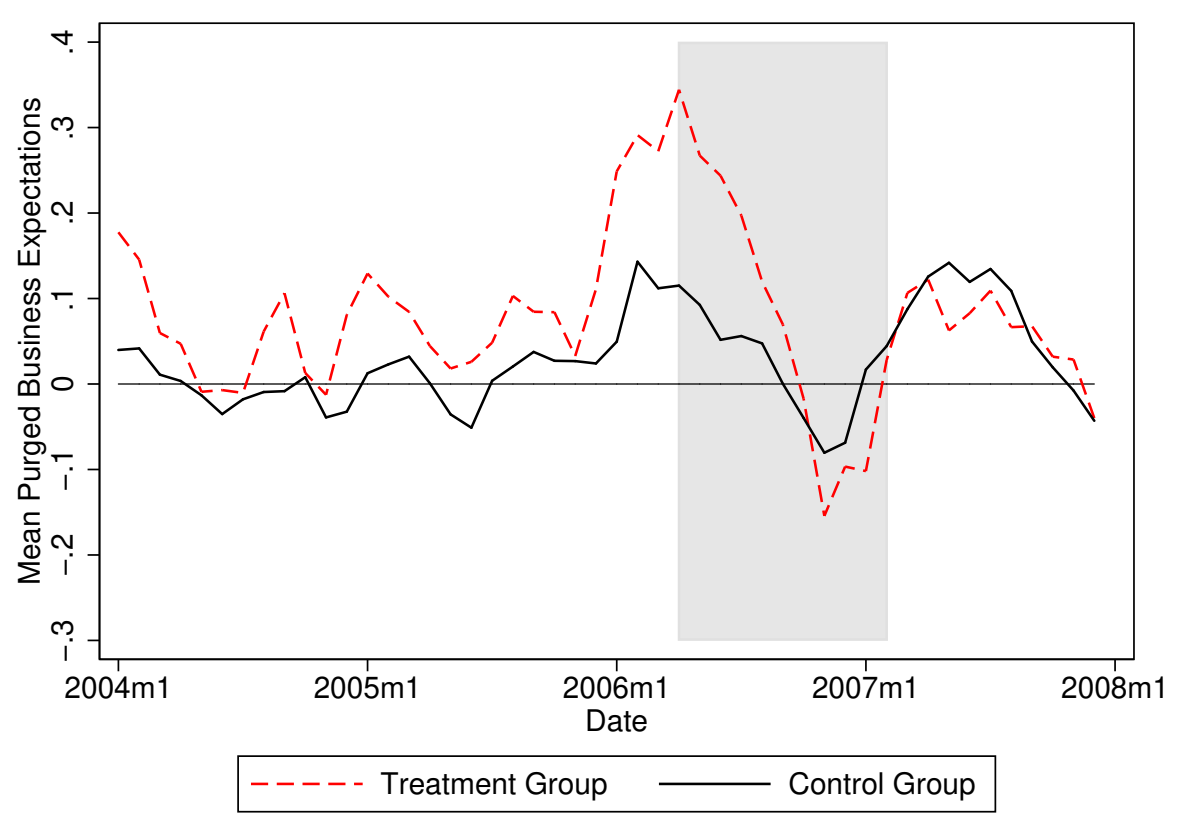

Notes: The dashed red line plots the mean of expectations for the next six months reported by the treated firms (durable good retailers), purged for past and current conditions and firm fixed effects. The solid black line plots the same variable for the firms in the control group (all other retail firms). The shaded area corresponds to the months when the six-month expectation window covers at least four months of the treatment period between July 2006 and June 2007, i.e., expectations reported between April 2006 and February 2007.

expectations to the VAT-induced differential treatment regarding the quality of information about future demand. In order to elicit whether firms "treated" with the information shock become more forward-looking once the time of the demand shock enters the expectation window of six months, we compute the difference-in-differences of the coefficients of both the future and the current/past realized business conditions. For this purpose, we extend the main empirical model (4) to the following standard DiD framework:

$$
\begin{aligned}
& \text { Expectations }_{i, t}^{+6 m}= \\
& \qquad \begin{array}{r}
\gamma_{\mathbf{1}}{ }^{\prime} \text { Conditions }_{i, t}+\gamma_{\mathbf{2}}{ }^{\prime} \text { Conditions }_{i, t} \times \mathbb{1}\left(\text { Durable }_{i}\right)+\gamma_{\mathbf{3}}{ }^{\prime} \text { Conditions }_{i, t} \times \mathbb{1}\left(\mathrm{VAT}_{t}\right) \\
+\boldsymbol{\delta}^{\prime} \text { Conditions }_{i, t} \times \mathbb{1}\left(\text { Durable }_{i}\right) \times \mathbb{1}\left(\mathrm{VAT}_{t}\right)+a_{t}+m_{i}+\varepsilon_{i, t} .
\end{array}
\end{aligned}
$$

As before, Expectations ${ }_{i, t}^{+6 m}$ captures firm $i$ 's expectations for the next six months as reported in the IBS. The column vector Conditions ${ }_{i, t}$ contains all measures of business conditions employed in the respective empirical specification. Moreover, the indicator $\mathbb{1}\left(\right.$ Durable $\left._{i}\right)$ equals one if the firm is a treated durable good retailer and zero otherwise. The indicator $\mathbb{1}\left(\mathrm{VAT}_{t}\right)$ equals one if $t \in[2006 m 4,2007 m 2]$, i.e., if the six-month expectation window covers at least four months of the treatment period between July 2006 and June 2007. Lastly, $a_{t}$ and $m_{i}$ denote the time and firm 
Table 5: The Effect of More Precise Information on Expectations: Main Results

\begin{tabular}{|c|c|c|c|c|c|}
\hline & \multicolumn{5}{|c|}{ Expected Business Conditions for the Next 6 Months } \\
\hline & \multirow[b]{2}{*}{$\begin{array}{l}\text { Diff-in-Diff } \\
\text { (1) }\end{array}$} & \multicolumn{2}{|c|}{ Treated Firms } & \multicolumn{2}{|c|}{ Control Firms } \\
\hline & & $\begin{array}{l}\text { VAT Period } \\
(2)\end{array}$ & $\begin{array}{c}\text { Control Period } \\
\text { (3) }\end{array}$ & $\begin{array}{l}\text { VAT Period } \\
\text { (4) }\end{array}$ & $\begin{array}{c}\text { Control Period } \\
(5)\end{array}$ \\
\hline Conditions $_{t+1, t+6}$ & $\begin{array}{l}0.18^{* * *} \\
(0.062)\end{array}$ & $\begin{array}{l}0.35^{* * *} \\
(0.038)\end{array}$ & $\begin{array}{l}0.23^{* * *} \\
(0.033)\end{array}$ & $\begin{array}{l}0.21^{* * *} \\
(0.039)\end{array}$ & $\begin{array}{l}0.27^{* * *} \\
(0.024)\end{array}$ \\
\hline Conditions $_{t, t-5}$ & $\begin{array}{c}-0.16^{* * *} \\
(0.050)\end{array}$ & $\begin{array}{l}0.15^{* * *} \\
(0.046)\end{array}$ & $\begin{array}{l}0.27^{* * *} \\
(0.036)\end{array}$ & $\begin{array}{l}0.29^{* * *} \\
(0.033)\end{array}$ & $\begin{array}{l}0.25^{* * *} \\
(0.030)\end{array}$ \\
\hline Adjusted $R^{2}$ & 0.472 & \multicolumn{4}{|c|}{0.472} \\
\hline Firm FE & yes & \multicolumn{4}{|c|}{ yes } \\
\hline Time FE & yes & \multicolumn{4}{|c|}{ yes } \\
\hline Observations & 26688 & \multicolumn{4}{|c|}{26688} \\
\hline
\end{tabular}

Notes: The table summarizes the results from two separate empirical models. Column (1) reports the estimate of the vector $\boldsymbol{\delta}$ in model (7), that is, the VAT-induced change in the coefficients of future realized business conditions $\left(\right.$ Conditions $\left._{t+1, t+6}\right)$ and of current/past conditions (Conditions $s_{t, t-5}$ ). The estimates of $\gamma_{\mathbf{1}}, \gamma_{\mathbf{2}}$, and $\gamma_{\mathbf{3}}$ are omitted. The reported estimates in Column (1) are given by the difference-in-differences of the absolute coefficients reported in Columns (2) through (5). The latter correspond to $\boldsymbol{\psi}_{\mathbf{1}}, \boldsymbol{\psi}_{\mathbf{2}}, \boldsymbol{\psi}_{\mathbf{3}}$, and $\boldsymbol{\psi}_{\mathbf{4}}$ in model (8). The treatment period (VAT period) includes expectations formed between April 2006 and February 2007. The treatment group comprises of all durable good retailers, and the control group comprises of all other retail firms. Standard errors are two-way clustered at the levels of firms and dates. Level of significance: ${ }^{*} p<0.10,{ }^{* *} p<0.05,{ }^{* * *} p<0.01$.

fixed effects, and $\varepsilon_{i, t}$ is the error term. ${ }^{28}$ The vector $\boldsymbol{\delta}$ contains the coefficients of interest that capture the treated firms' adjustment of expectations in response to the VAT-induced information shock.

\subsection{The Causal Effect of More Precise Information on Expectations}

In a first step, we estimate the adjustments in the weights that durable goods retailers put on disaggregate information regarding their future businesses as well as current and past conditions when forming their expectations. Hence, the column vector Conditions ${ }_{i, t}$ in model (7) equals $\left(\text { Conditions }_{i,(t+1, t+6)} \text {, Conditions } i,(t-5, t)\right)^{T}$.

Column (1) of Table 5 reports the vector of the estimated treatment effects $(\hat{\boldsymbol{\delta}})$ and documents the main result of this section: firms "treated" with the shock become significantly more forward-looking once the time of the demand shock enters the six-month expectation window. This manifests itself in a statistically highly significant increase of 0.18 in the weights that durable goods retailers put on Conditions $s_{i,(t+1, t+6)}$, the proxy for disaggregate information, when forming their expectations. Hence, the expectations of firms are almost twice as sensitive to disaggregate information about future business conditions compared to periods with "average" fluctuations. ${ }^{29}$ At the same time, the

\footnotetext{
${ }^{28}$ Note that all retail firms (with the exception of car sellers) belong to the same two-digit sector according to the German industry classification system of 2003. The time fixed effects capturing the aggregate effects for the retail sector here are thus of comparable dimension as the ones in Panel C of Table 2.

${ }^{29}$ Table 12 in Appendix C.1 performs an analysis of retail firms' expectation formation along the lines of Section 4.
} 
weight on current and past business conditions (Conditions ${ }_{i,(t, t-5)}$ ) becomes considerably smaller and decreases by 0.16 .

Next, we confirm that the treatment effect is driven by a change in behavior of the treated firms during the treatment period (as opposed to a change in behavior of the control firms). To this end, we estimate the effects of disaggregate information, proxied by Conditions ${ }_{i,(t+1, t+6)}$, and the effect of current and past trends, Conditions ${ }_{i,(t, t-5)}$, on expectations separately for the treated and control firms during the treatment and control periods. This is achieved via the following empirical model

$$
\begin{aligned}
& \text { Expectations }_{i, t}^{+6 m}= \\
& \begin{array}{r}
\psi_{\mathbf{1}}^{\prime} \text { Conditions }_{i, t} \times \mathbb{1}\left(\text { Durable }_{i}\right) \times \mathbb{1}\left(\mathrm{VAT}_{t}\right)+\boldsymbol{\psi}_{\mathbf{2}}^{\prime} \text { Conditions }_{i, t} \times \mathbb{1}\left(\text { Durable }_{i}\right) \times \mathbb{1}\left(\text { no VAT }_{t}\right) \\
+\boldsymbol{\psi}_{\mathbf{3}}^{\prime} \text { Conditions }_{i, t} \times \mathbb{1}\left(\text { Non-Durable }_{i}\right) \times \mathbb{1}\left(\mathrm{VAT}_{t}\right)+\boldsymbol{\psi}_{\mathbf{4}}^{\prime} \text { Conditions }_{i, t} \times \mathbb{1}\left(\text { Non-Durable }_{i}\right) \\
\times \mathbb{1}\left(\text { no VAT }_{t}\right)+a_{t}+m_{i}+\varepsilon_{i, t}, \quad(8)
\end{array}
\end{aligned}
$$

where the indicators $\mathbb{1}($ Non-Durable $i)$ and $\mathbb{1}\left(\right.$ no $\left.\mathrm{VAT}_{t}\right)$ equal one if their counterparts $\mathbb{1}\left(\right.$ Durable $\left._{i}\right)$ and $\mathbb{1}\left(\mathrm{VAT}_{t}\right)$ are zero. It is straightforward to see that the differences-in-differences of the coefficients from model (8) deliver the same treatment effects as directly estimated in model (7), i.e., $\boldsymbol{\delta}=\left(\boldsymbol{\psi}_{\mathbf{1}}-\boldsymbol{\psi}_{\mathbf{2}}\right)-\left(\boldsymbol{\psi}_{\mathbf{3}}-\boldsymbol{\psi}_{\mathbf{4}}\right)$.

The results of estimating (8) in Table 5, Columns (2) through (5), strongly confirm that the treated firms become more forward-looking in response to the VAT-induced increase in the quality of disaggregate information. When the VAT-induced demand shock does not enter the six-month expectation window, the expectations of durable goods retailers (Column (3)) and all other retail firms (Column (5)) reflect disaggregate information as well as current and past business conditions in a comparable manner. Moreover, the forecasting behavior of the control firms remains stable between the treatment and control periods (Columns (4) and (5)). In contrast, treated firms largely rely on disaggregate information about their future businesses when they form their expectations during the treatment period with the corresponding coefficient increasing to 0.35 (Column (2)). At the same time, the sensitivity of expectations with respect to variation in current/past conditions, Conditions $_{i,(t, t-5)}$, substantially drops to 0.15 . This confirms, hence, that the shift in attention of the treated firms towards information about the future cannot be attributed to general adjustments of the expectation formation process of all retail firms.

\subsection{The VAT-Induced Disaggregate Demand Shock Is Anticipated Early On}

In a next step, we investigate whether the information about the VAT-induced disaggregate demand shock is reflected in the expectations well ahead of the shocks. For this purpose, we decompose the proxy for disaggregate information, Conditions $_{i,(t+1, t+6)}$, into information about business conditions two quarter ahead $\left(\right.$ Conditions $\left._{i,(t+1, t+3)}\right)$ and information about business conditions one quarter ahead $\left(\right.$ Conditions $\left._{i,(t+4, t+6)}\right)$. We proceed similarly with Conditions ${ }_{i,(t-5, t)}$.

Table 6 reports the results of estimating models (7) and (8) after inclusion of the more fine-tuned 
Table 6: The Effect of More Precise Information on Expectations: Extended Results

\begin{tabular}{|c|c|c|c|c|c|}
\hline & \multicolumn{5}{|c|}{ Expected Business Conditions for the Next 6 Months } \\
\hline & \multirow[b]{2}{*}{$\begin{array}{l}\text { Diff-in-Diff } \\
\text { (1) }\end{array}$} & \multicolumn{2}{|c|}{ Treated Firms } & \multicolumn{2}{|c|}{ Control Firms } \\
\hline & & $\begin{array}{c}\text { VAT Period } \\
(2)\end{array}$ & $\begin{array}{c}\text { Control Period } \\
\text { (3) }\end{array}$ & $\begin{array}{c}\text { VAT Period } \\
(4)\end{array}$ & $\begin{array}{c}\text { Control Period } \\
(5)\end{array}$ \\
\hline Conditions $_{t+4, t+6}$ & $\begin{array}{l}0.17^{* * *} \\
(0.053)\end{array}$ & $\begin{array}{l}0.17^{* * *} \\
(0.034)\end{array}$ & $\begin{array}{c}0.030 \\
(0.028)\end{array}$ & $\begin{array}{l}0.052^{*} \\
(0.029)\end{array}$ & $\begin{array}{c}0.076^{* * *} \\
(0.019)\end{array}$ \\
\hline Conditions $_{t+1, t+3}$ & $\begin{array}{c}0.014 \\
(0.046)\end{array}$ & $\begin{array}{l}0.14^{* * *} \\
(0.029)\end{array}$ & $\begin{array}{l}0.14^{* * *} \\
(0.022)\end{array}$ & $\begin{array}{l}0.16^{* * *} \\
(0.023)\end{array}$ & $\begin{array}{l}0.18^{* * *} \\
(0.015)\end{array}$ \\
\hline Conditions $_{t, t-2}$ & $\begin{array}{l}-0.11^{* *} \\
(0.056)\end{array}$ & $\begin{array}{l}0.16^{* * *} \\
(0.045)\end{array}$ & $\begin{array}{l}0.27^{* * *} \\
(0.028)\end{array}$ & $\begin{array}{l}0.25^{* * *} \\
(0.027)\end{array}$ & $\begin{array}{l}0.25^{* * *} \\
(0.024)\end{array}$ \\
\hline Conditions $_{t-3, t-5}$ & $\begin{array}{l}-0.048 \\
(0.041)\end{array}$ & $\begin{array}{l}-0.012 \\
(0.033)\end{array}$ & $\begin{array}{l}0.0018 \\
(0.021)\end{array}$ & $\begin{array}{l}0.0098 \\
(0.023)\end{array}$ & $\begin{array}{l}-0.025 \\
(0.019)\end{array}$ \\
\hline Adjusted $R^{2}$ & 0.482 & \multicolumn{4}{|c|}{0.482} \\
\hline Firm FE & yes & \multicolumn{4}{|c|}{ yes } \\
\hline Time FE & yes & \multicolumn{4}{|c|}{ yes } \\
\hline Observations & 24798 & \multicolumn{4}{|c|}{24798} \\
\hline
\end{tabular}

Notes: The table summarizes the results from two separate empirical models. Column (1) reports the estimate of the vector $\boldsymbol{\delta}$ in model (7), that is, the VAT-induced change in the coefficients of business conditions two quarters ahead $\left(\right.$ Conditions $\left._{t+4, t+6}\right)$, of business conditions one quarter ahead (Conditions $s_{t+1, t+3}$ ) and of the current quarter's and the past quarter's conditions (Conditions ${ }_{t, t-2}$ and Conditions $t_{t-3, t-5}$, respectively). The estimates of $\gamma_{\mathbf{1}}, \gamma_{\mathbf{2}}$, and $\gamma_{\mathbf{3}}$ are omitted. The reported estimates in Column (1) are given by the difference-in-differences of the absolute coefficients reported in Columns (2) through (5). The latter correspond to $\boldsymbol{\psi}_{\mathbf{1}}, \boldsymbol{\psi}_{\mathbf{2}}, \boldsymbol{\psi}_{\mathbf{3}}$, and $\boldsymbol{\psi}_{\mathbf{4}}$ in model (8). The treatment period (VAT period) includes expectations formed between April 2006 and February 2007. The treatment group comprises of all durable good retailers and the control group comprises of all other retail firms. Standard errors are two-way clustered at the levels of firms and dates. Level of significance: ${ }^{*} p<0.10,{ }^{* *} p<0.05,{ }^{* * *} p<0.01$.

proxies for disaggregate information. ${ }^{30}$ During "normal" times (Columns (3) and (5)), the two quarter ahead business conditions are only weakly reflected in expectations although firms are asked for their assessment of the next six months. Accordingly, information about business conditions in the near future appears to be more strongly reflected in the expectations than information about the more distant future. Note, moreover, that expectations are also strongly associated with current conditions.

In contrast, at the time of the information shock, the treated firms incorporate information about the VAT-induced demand shock into their expectations well ahead of the shocks, while expectations of unaffected firms remain widely unchanged (Columns (2) and (4)). Strikingly, during the treatment period, the disaggregate information about business conditions two quarters ahead is also associated more strongly with expectations than the treated firms' information about the

\footnotetext{
${ }^{30}$ The column vector Conditions C $_{i, t}$ in models (7) and (8) now contains Conditions ${ }_{i,(t+4, t+6)}$, Conditions $_{i,(t+1, t+3)}$, Conditions $_{i,(t, t-2)}$, and Conditions $i_{i, t-3, t-5)}$. Note that we use the same definition of $\mathbb{1}\left(\mathrm{VAT}_{t}\right)$ as independent variables as in the specification with six-month moving averages of business conditions, so that the interaction terms of Conditions $s_{i,(t+1, t+3)} \times \mathbb{1}\left(\mathrm{VAT}_{t}\right)$ and Conditions ${ }_{i,(t+4, t+6)} \times \mathbb{1}\left(\mathrm{VAT}_{t}\right)$ refer to realized business conditions during different phases of the shock. A specification with adjusted dummies for the treatment period that accounts for this issue does not deliver substantially different results. These results are available from the authors on request.
} 
current as well as the one quarter ahead business conditions.

This pattern is also reflected in DiD coefficients in Column (1). The weight that durable goods retailers put on information about business conditions two quarters ahead increases substantially by 0.17 . At the same time, the weight on the proxy for information about business conditions one quarter ahead (Conditions ${ }_{i,(t+1, t+3)}$ ) remains virtually unaffected, and the weight on current conditions drops substantially by $0.11 .^{31}$

We conclude that the firms "treated" by the VAT-induced increase in the quality of information become significantly more forward-looking once the time of the disaggregate demand shock enters their six-month expectation window. Appendix C.2 shows that this result is not driven by the choice of the baseline specification. Specifically, the results are robust to the definition of the treatment period (Panel A of Table 13), the inclusion of wholesale firms to the control group (Panel B), as well as different restrictions on the minimum duration of firms in the sample or controlling for attrition (Panel C). Moreover, the results are robust to restricting the sample to the period used in Section 4 (Panel D) as well as to the specification of time fixed effects (Panel E).

\section{Conclusion}

This paper studies how firms form expectations regarding their own future business conditions. The first contribution is to document that disaggregate information, proxied by firms' future business conditions uncorrelated with aggregate information at high-dimensional industry levels, is strongly reflected in the expectations. We also show that disaggregate information explains an economically significant share of the variance in expectations. This is important, because relying predominantly on aggregate information or sentiment may lead to the amplification of business cycles. It remains an open question, however, whether firms put a sufficiently high (or low) weight on disaggregate information. Studying this question requires knowledge about the precision of disaggregate and aggregate information, which is hard to measure.

The paper's second contribution is to provide causal evidence of how the expectations of firms react to new information about a large disaggregate demand shock: the anticipation effect in demand for durable goods in response to a pre-announced VAT increase in Germany. Exploiting the similarity of durable and non-durable goods retailers in a difference-in-differences design, we find that firms "treated" with the shock become significantly more forward-looking ahead of the large shifts in demand. In particular, when the information about the shock becomes relevant, durable goods retailers put a larger weight on the information about the business conditions two quarters ahead when forming their expectations and rely substantially less on information about their current businesses.

The documented adjustment of expectation formation can be explained by two rational responses to the VAT-induced increase in the quality of information. One the one hand, firms may rationally

\footnotetext{
${ }^{31}$ This result also holds when estimating model (7) with monthly measures of realized business conditions. In this setting, the monthly DiD coefficients are amplified in particular in the months $t+5$ and $t+6$, but are close to zero in the months $t+7$ and later. The results are available from the authors on request.
} 
put more weight on more distant shocks at times when these shocks can be predicted more reliably. Similarly, at times when large swings in demand are to be expected, firms should view current conditions as less reliable signals for future conditions and thus weight them less when forming expectations. On the other hand, the shift in weights may reflect a shift in attention to more distant realizations of shocks. As predicted by theories of rational inattention by Sims (2003), Woodford (2003), and Maćkowiak and Wiederholt (2009, 2015), such shifts may occur if information regarding business conditions in the more distant future becomes either more informative or more cheaply to process. This is likely to be true for the case of the VAT shock.

One way to disentangle these two effects in future work could be to study the adjustment process of firms' expectations in response to pre-announced shocks that vary in their information content or magnitude. If firms were constrained in their ability to gather and process information, these variations should lead to differential costs and benefits of adjusting expectations to those shocks, and, hence, to differential adjustments of expectations conditional on the information structure of the shock. In contrast, unconstrained firms are expected to unconditionally adjust their expectations

to shocks. A challenge for this approach is, however, that suitable shocks are notoriously hard to identify. Thus, one would likely have to abandon some credibility in the identification strategyrelative to the cleanly identified VAT shock used in this paper-in order to perform analyses of this sort. We leave this challenge to future work.

\section{References}

Abberger, K., M. Birnbrich, and C. Seiler (2009): "Der »Test des Tests« im Handel-eine Metaumfrage zum ifo Konjunkturtest," ifo Schnelldienst, 62(21), 34-41.

Andrade, P., And H. Le Bihan (2013): "Inattentive Professional Forecasters," Journal of Monetary Economics, 60(8), 967-982.

Ang, A., G. Bekaert, And M. Wei (2007): "Do Macro Variables, Asset Markets, or Surveys Forecast Inflation Better?," Journal of Monetary Economics, 54(4), 1163-1212.

Angeletos, G.-M., and J. LA'O (2013): "Sentiments," Econometrica, 81(2), 739-779.

Angrist, J. D., And J.-S. Pischke (2008): Mostly Harmless Econometrics: An Empiricist's Companion. Princeton University Press.

Armantier, O., S. Nelson, G. Topa, W. van der Klaauw, and B. Zafar (2016): "The Price Is Right: Updating Inflation Expectations in a Randomized Price Information Experiment," Review of Economics and Statistics, 98(3), 503-523.

Armona, L. C., A. Fuster, and B. Zafar (2016): "Home Price Expectations and Behavior: Evidence from a Randomized Information Experiment," FED New York Staff Report, 798. 
Bacchetta, P., E. Mertens, and E. Van Wincoop (2009): "Predictability in Financial Markets: What Do Survey Expectations Tell Us?," Journal of International Money and Finance, 28(3), 406-426.

Bachmann, R., and S. Elstner (2015): "Firm Optimism and Pessimism," European Economic Review, 79, 297-325.

Bachmann, R., S. Elstner, and A. Hristov (2017): "Surprise, Surprise-Measuring Firm-level Investment Innovations," Journal of Economic Dynamics and Control, 83, 107-148.

Bachmann, R., S. Elstner, and E. R. Sims (2013): "Uncertainty and Economic Activity: Evidence from Business Survey Data," American Economic Journal: Macroeconomics, 5(2), 217-249.

Beaudry, P., And F. Portier (2014): "News-driven Business Cycles: Insights and Challenges," Journal of Economic Literature, 52(4), 993-1074.

Becker, S. O., And K. Wohlrabe (2008): "Micro Data at the Ifo Institute for Economic Research - The 'Ifo Business Survey' Usage and Access," Schmollers Jahrbuch-Zeitschrift für Wirtschafts- und Sozialwissenschaften, 128(2), 307-319.

Ben-David, I., J. R. Graham, and C. R. Harvey (2013): "Managerial Miscalibration," Quarterly Journal of Economics, 128(4), 1547-1584.

Bundesbank (2008): "Price and Volume Effects of VAT Increase on 1 January 2007," in Monthly Report April 2008, pp. 29-46.

Cameron, A. C., J. B. Gelbach, and D. L. Miller (2011): "Robust Inference with Multiway Clustering," Journal of Business \&5 Economic Statistics, 29(2), 238-249.

Carare, A., and S. Danninger (2008): "Inflation Smoothing and the Modest Effect of VAT in Germany," IMF Working Papers, 08/175.

Cavallo, A., G. Cruces, and R. Perez-Truglia (2017): "Inflation Expectations, Learning, and Supermarket Prices: Evidence from Survey Experiments," American Economic Journal: Macroeconomics, 9(3), 1-35.

CDU/CSU (2005): "Deutschlands Chancen nutzen. Wachstum. Arbeit. Sicherheit.," Electoral Manifest.

Coibion, O., And Y. Gorodnichenko (2012): "What Can Survey Forecasts Tell Us about Information Rigidities?," Journal of Political Economy, 120(1), 116-159.

(2015): "Information Rigidity and the Expectations Formation Process: A Simple Framework and New Facts," American Economic Review, 105(8), 2644-2678. 
Coibion, O., Y. Gorodnichenko, and S. Kumar (2015): "How Do Firms Form Their Expectations? New Survey Evidence," NBER Working Paper 21092.

D’Acunto, F., D. Hoang, and M. Weber (2016): "Unconventional Fiscal Policy, Inflation Expectations, and Consumption Expenditure," Working Paper.

Destatis (2003): "German Classification of Economic Activities, Edition 2003 (WZ 2003)," .

Dovern, J., U. Fritsche, P. Loungani, and N. Tamirisa (2015): "Information Rigidities: Comparing Average and Individual Forecasts for a Large International Panel," International Journal of Forecasting, 31(1), 144-154.

Dube, A., T. W. Lester, And M. Reich (2010): "Minimum Wage Effects Across State Borders: Estimates Using Contiguous Counties," Review of Economics and Statistics, 92(4), 945-964.

Ehrmann, M., and P. Tzamourani (2012): "Memories of High Inflation," European Journal of Political Economy, 28(2), 174-191.

Faust, J., And J. H. Wright (2013): "Forecasting Inflation," Handbook of Economic Forecasting, 2(Part A), 3-56.

Fernández-Val, I., And M. Weidner (2016): "Individual and Time Effects in Nonlinear Panel Models with Large N, T," Journal of Econometrics, 192(1), 291-312.

Fuhrer, J. C. (2015): "Expectations as a Source of Macroeconomic Persistence: An Exploration of Firms' and Households' Expectation Formation," FRB of Boston Working Paper, 15-5.

Gabaix, X. (2011): "The Granular Origins of Aggregate Fluctuations," Econometrica, 79(3), $733-772$.

Gennaioli, N., Y. Ma, And A. Shleifer (2015): "Expectations and Investment," NBER Macroeconomics Annual, 30(1), 379-431.

Greenwood, R., And A. Shleifer (2014): "Expectations of Returns and Expected Returns," Review of Financial Studies, 27(3), 714-746.

Hellwig, C., and L. Veldkamp (2009): "Knowing What Others Know: Coordination Motives in Information Acquisition," Review of Economic Studies, 76(1), 223-251.

Huettner, F., And M. Sunder (2012): "Axiomatic Arguments for Decomposing Goodness of Fit According to Shapley and Owen Values," Electronic Journal of Statistics, 6, 1239-1250.

IBS-IND (2015): Ifo Business Survey Industry 1/1980 - 12/2015. LMU-ifo Economics \& Business Data Center, Munich, doi: 10.7805/ebdc-ibs-ind-2015b.

IBS-SERV (2015): Ifo Business Survey Service Sector 10/2004 - 12/2015. LMU-ifo Economics \& Business Data Center, Munich, doi: 10.7805/ebdc-ibs-serv-2015b. 
IBS-TRA (2015): Ifo Business Survey Trade 1/1990 - 12/2015. LMU-ifo Economics \& Business Data Center, Munich, doi: 10.7805/ebdc-ibs-tra-2015b.

Iто, T. (1990): "Foreign Exchange Rate Expectations: Micro Survey Data," American Economic Review, 80(3), 434-449.

König, H., M. Nerlove, and G. Oudiz (1981): "On the Formation of Price Expectations: An Analysis of Business Test Data by Log-linear Probability Models," European Economic Review, 16(1), 103-138.

Kuchler, T., And B. Zafar (2015): "Personal Experiences and Expectations about Aggregate Outcomes," Federal Reserve Bank of New York Staff Reports, 748.

Link, S. (2017): "Harmonization and Interpretation of the Ifo Business Survey's Micro Data," Working Paper.

Maćkowiak, B., and M. Wiederholt (2009): "Optimal Sticky Prices under Rational Inattention," American Economic Review, 99(3), 769-803.

- (2015): "Business Cycle Dynamics under Rational Inattention," Review of Economic Studies, 82(4), 1502-1532.

Malmendier, U., And S. Nagel (2016): "Learning from Inflation Experiences," Quarterly Journal of Economics, 131(1), 53-87.

Mankiw, N. G., And R. Reis (2002): "Sticky Information versus Sticky Prices: A Proposal to Replace the New Keynesian Phillips Curve," Quarterly Journal of Economics, 117(4), 1295-1328.

Mankiw, N. G., R. Reis, and J. Wolfers (2004): "Disagreement About Inflation Expectations," in NBER Macroeconomics Annual 2003, Volume 18, pp. 209-270. The MIT Press.

Massenot, B., and Y. Pettinicchi (forthcoming): "Can Firms See Into the Future? Survey Evidence from Germany," Journal of Economic Behavior and Organization.

MCFAdDen, D. (1973): "Conditional Logit Analysis of Qualitative Choice Behavior," Frontiers in Econometrics, pp. 105-142.

Nerlove, M. (1983): "Expectations, Plans, and Realizations in Theory and Practice," Econometrica, 51(5), 1251-1279.

Neyman, J., and E. L. Scott (1948): "Consistent Estimates Based on Partially Consistent Observations," Econometrica: Journal of the Econometric Society, pp. 1-32.

Patton, A. J., And A. Timmermann (2010): "Why Do Forecasters Disagree? Lessons from the Term Structure of Cross-sectional Dispersion," Journal of Monetary Economics, 57(7), 803-820. 
Pesaran, M. H., and M. Weale (2006): "Survey Expectations," Handbook of Economic Forecasting, 1, 715-776.

Ravn, M. O., and H. Uhlig (2002): "On Adjusting the Hodrick-Prescott Filter for the Frequency of Observations," Review of Economics and Statistics, 84(2), 371-376.

Riedl, M., And I. Geishecker (2014): "Keep It Simple: Estimation Strategies for Ordered Response Models with Fixed Effects," Journal of Applied Statistics, 41(11), 2358-2374.

Shorrocks, A. F. (2013): "Decomposition Procedures for Distributional Analysis: a Unified Framework Based on the Shapley Value," Journal of Economic Inequality, 11(1), 99-126.

Sims, C. A. (2003): "Implications of Rational Inattention," Journal of Monetary Economics, 50(3), 665-690.

SPD (2005): "Vertrauen in Deutschland. Das Wahlmanifest der SPD," Electoral Manifest.

Triebs, T. P., And J. Tumlinson (2016): "Learning Capitalism the Hard Way - Evidence from German Reunification," CESifo Working Paper, 6260.

Veldkamp, L., And J. Wolfers (2007): “Aggregate Shocks or Aggregate Information? Costly Information and Business Cycle Comovement," Journal of Monetary Economics, 54, 37-55.

Woodford, M. (2003): "Imperfect Common Knowledge and the Effects of Monetary Policy," Knowledge, Information, and Expectations in Modern Macroeconomics: In Honor of Edmund S. Phelps, edited by P. Aghion, R. Frydman, J. Stiglitz, and M. Woodford. Princeton, NJ: Princeton Univ. Press. 


\title{
Appendix (for Online Publication Only)
}

\author{
A. Appendix to Section 2: Additional Tables
}

Table 7: Attrition

\begin{tabular}{lcccccccccccc}
\hline & & \multicolumn{10}{c}{ Fraction of Firms Surviving (in \%) } \\
Start Date & Firms@Start & $6 \mathrm{~m}$ & 1yr & 2yrs & 3yrs & 4yrs & 5yrs & $6 y r s$ & $7 \mathrm{yrs}$ & 8yrs & $9 \mathrm{yrs}$ & $10 \mathrm{yrs}$ \\
\hline $2005 \mathrm{~m} 3$ & 5701 & 95.5 & 91.2 & 83.9 & 78.2 & 72.7 & 67.9 & 63.8 & 59.6 & 55.4 & 51.2 & 46.6 \\
$2006 \mathrm{~m} 3$ & 6510 & 95.6 & 91.2 & 84.6 & 78.3 & 73.0 & 68.3 & 63.7 & 59.1 & 54.5 & 49.5 & 0 \\
$2007 \mathrm{~m} 3$ & 6822 & 95.5 & 92.1 & 85.1 & 78.9 & 73.9 & 69.0 & 63.9 & 58.8 & 53.4 & 0 & 0 \\
$2008 \mathrm{~m} 3$ & 6974 & 96.0 & 92.1 & 85.4 & 79.9 & 74.4 & 69.0 & 63.3 & 57.4 & 0 & 0 & 0 \\
$2009 \mathrm{~m} 3$ & 7356 & 95.9 & 92.6 & 86.5 & 80.5 & 74.5 & 68.2 & 61.7 & 0 & 0 & 0 & 0 \\
$2010 \mathrm{~m} 3$ & 7752 & 96.2 & 93.0 & 86.3 & 79.5 & 72.8 & 65.9 & 0 & 0 & 0 & 0 & 0 \\
$2011 \mathrm{~m} 3$ & 7827 & 96.4 & 92.5 & 85.3 & 78.1 & 70.5 & 0 & 0 & 0 & 0 & 0 & 0 \\
$2012 \mathrm{~m} 3$ & 8069 & 95.6 & 91.8 & 83.4 & 75.0 & 0 & 0 & 0 & 0 & 0 & 0 & 0 \\
$2013 \mathrm{~m} 3$ & 7880 & 95.0 & 90.5 & 81.4 & 0 & 0 & 0 & 0 & 0 & 0 & 0 & 0 \\
$2014 \mathrm{~m} 3$ & 7468 & 94.5 & 89.6 & 0 & 0 & 0 & 0 & 0 & 0 & 0 & 0 & 0 \\
$2015 \mathrm{~m} 3$ & 6983 & 88.9 & 0 & 0 & 0 & 0 & 0 & 0 & 0 & 0 & 0 & 0 \\
\hline
\end{tabular}

Notes: This table displays, for all firms in our sample in March of each year, the percentages of firms that remain in the sample after the passage of different time intervals (between six months and ten years). 
Table 8: Transition Frequencies by Sector

\begin{tabular}{lcccc|ccc}
\hline & \multicolumn{7}{c}{ Panel A: Manufacturing } \\
& & \multicolumn{7}{c}{ Conditions Next Period } & \multicolumn{2}{c}{ Expectations Next Period } \\
\hline & & 1 & 0 & -1 & 1 & 0 & -1 \\
\hline Current & 1 & 0.228 & 0.055 & 0.002 & 0.113 & 0.069 & 0.007 \\
Conditions/ & 0 & 0.055 & 0.431 & 0.041 & 0.067 & 0.500 & 0.064 \\
Expectations & -1 & 0.002 & 0.041 & 0.145 & 0.009 & 0.062 & 0.108 \\
\hline & Sum & 0.285 & 0.527 & 0.188 & 0.189 & 0.631 & 0.179 \\
\hline
\end{tabular}

Panel B: Services

\begin{tabular}{lc|ccc|ccc} 
& & \multicolumn{3}{|c|}{ Conditions Next Period } & \multicolumn{3}{c}{ Expectations Next Period } \\
\hline & & 1 & 0 & -1 & 1 & 0 & -1 \\
\hline Current & 1 & 0.284 & 0.072 & 0.003 & 0.167 & 0.087 & 0.008 \\
Conditions/ & 0 & 0.072 & 0.391 & 0.037 & 0.084 & 0.462 & 0.053 \\
Expectations & -1 & 0.003 & 0.037 & 0.102 & 0.010 & 0.051 & 0.079 \\
\hline & Sum & 0.359 & 0.500 & 0.142 & 0.261 & 0.600 & 0.140 \\
\hline
\end{tabular}

Panel C: Retail and Wholesale

\begin{tabular}{lc|ccc|ccc} 
& & \multicolumn{3}{|c|}{ Conditions Next Period } & \multicolumn{3}{c}{ Expectations Next Period } \\
\hline & & 1 & 0 & -1 & 1 & 0 & -1 \\
\hline Current & 1 & 0.156 & 0.067 & 0.006 & 0.103 & 0.061 & 0.006 \\
Conditions/ & 0 & 0.067 & 0.402 & 0.067 & 0.059 & 0.477 & 0.071 \\
Expectations & -1 & 0.006 & 0.068 & 0.162 & 0.006 & 0.071 & 0.146 \\
\hline & Sum & 0.229 & 0.537 & 0.235 & 0.168 & 0.609 & 0.223 \\
\hline
\end{tabular}

Notes: This table shows the transition frequencies of reported realized business conditions and expected business conditions for each industry survey. The left (right) panel shows the frequencies of reported business conditions (expected business conditions) in the next reported month for each possible current report of business conditions/expectations. Since these statistics are derived from the time dimension of the panel dataset, the overall frequencies of reported future conditions/expectations displayed in the last row $(S u m)$ are equal to the overall frequencies for the current conditions/expectations, which are, for this reason, omitted.

\section{B. Robustness Checks for Section 4: Panel Results}

\section{B.1. Fixed Effects Logit and OLS with Binarized Expectations Data}

In the main text, we estimate the association between expectations and disaggregate information (proxied by the future realized business conditions following the argument in Section 3.1) via OLS despite the discrete nature of the data on expectations. We do so, because the linear model has the key advantage that it allows for the efficient estimation of high-dimensional fixed effects, which is key to our empirical strategy as outlined in Section 3. The linear model also allows for a straight-forward decomposition of the variance explained in Section 4.3 and for exploiting the natural experiment in Section 5 via a difference-in-differences design.

This section demonstrates that, in our setting, empirical models for discrete data, while being 
less parsimonious than the linear model, deliver almost identical estimates as the OLS estimator used in the main text. To this end, we estimate a variant of the main empirical model (4) with binarized versions of the dependent variable. In its first binarized version, the dependent variable equals one if expectations are good (that is, if Expectations $t_{t}^{+6 m}=1$ ) and equals zero if expectations are either normal or bad (that is, if Expectations ${ }_{t}^{+6 m} \in\{-1,0\}$ ). In its second binarized version, the dependent variable equals one if expectations are normal or good (that is, if Expectations $t_{t}^{+6 m} \in$ $\{0,1\}$ ) and equals zero if expectations are bad (that is, if Expectations $t_{t}^{+6 m}=-1$ ).

These binary dependent variables allow us to estimate (4) both via OLS, as in the main text, and via fixed effect logit. Since (4) includes several fixed effects - in the firm and in the time dimension - the logit estimates are biased due to the incidental parameters problem (Neyman and Scott, 1948). ${ }^{32}$ For this reason, we correct the logit estimates via the analytical bias correction suggested by Fernández-Val and Weidner (2016).

Table 9 compares the OLS estimates and the average partial effects of the logit estimates for the variant of (4) with binary dependent variables. Clearly, OLS and logit deliver very similar estimates of all coefficients: the absolute difference between the logit and the OLS estimate is, at most, 0.03. This result is not surprising, given that Figure 1 in Section 4.1 shows that the linear approximation of the mean in expectations conditional on future realized business conditions (the proxy for disaggregate information) fits the data well. Both empirical models also perform similarly in terms of the precision of the estimates (as indicated by their standard errors) and the model fit (as indicated by the $R^{2}$ and the Pseudo $R^{2}$, respectively). Finally, note that the smaller magnitude of the effects in Table 9 compared to Column (5) of Table 2 is due to the fact that a given increase in the binarized dependent variable represents, on average, a bigger shift in expectations than an increase of the same magnitude in the original expectations data used in the main text.

We conclude that the OLS and logit estimates are nearly indistinguishable in our setting, so that estimating linear models seemingly comes at little costs despite the discrete nature of the dependent variable.

\section{B.2. Fixed Effects, Attrition, and Additional Controls}

This section confirms that the main results of Section 4, which are documented in Column (5) of Table 2, remain unchanged when exposed to a variety of robustness checks. Columns (2), (3), and (4) of Table 10 document that the coefficient of the disaggregate components of Conditions ${ }_{i,(t+1, t+6)}$ is unaffected by the specification of the time fixed effect that controls for aggregate information. Relative to the baseline specification in Column (1), the change in the estimated coefficient of Conditions $_{i,(t+1, t+6)}$ never exceeds 0.01 . This holds regardless of whether we control only for a single aggregate time fixed effect in Column (2), 180 time fixed effects at the three-digit industry level in Column (3), or whether we add 16 time fixed effects, one for each German federal state, in

\footnotetext{
${ }^{32}$ Specifically, either of the fixed effects $m_{i}$ or $a_{t} \times \mathbb{1}\left(\right.$ Subsector $\left._{i}\right)$ cannot be consistently identified in samples in which $N \rightarrow \infty$ or $T \rightarrow \infty$. The inconsistent estimates of $m_{i}$ or $a_{t} \times \mathbb{1}$ (Subsector (Sul $_{i}$ cause biased estimates of the remaining parameters due to the non-linear nature of the logit transformation of (4).
} 
Table 9: Panel Regressions: Fixed Effects Logit and OLS with Binarized Data

\begin{tabular}{|c|c|c|c|c|}
\hline & \multicolumn{2}{|c|}{$\mathbb{1}\left(\right.$ Expectations $\left._{t}^{+6 m}=1\right)$} & \multicolumn{2}{|c|}{$\mathbb{1}\left(\right.$ Expectations $\left._{t}^{+6 m} \neq-1\right)$} \\
\hline & OLS & Logit & OLS & Logit \\
\hline & $(1)$ & $(2)$ & $(3)$ & $(4)$ \\
\hline & \multicolumn{4}{|c|}{ Panel A: Manufacturing } \\
\hline Conditions $_{t+1, t+6}$ & $\begin{array}{c}0.13^{* * *} \\
(0.0020)\end{array}$ & $\begin{array}{c}0.12^{* * *} \\
(0.0025)\end{array}$ & $\begin{array}{c}0.17^{* * *} \\
(0.0019)\end{array}$ & $\begin{array}{c}0.16^{* * *} \\
(0.0030)\end{array}$ \\
\hline Conditions $_{t, t-5}$ & $\begin{array}{r}-0.081^{* * *} \\
(0.0020)\end{array}$ & $\begin{array}{r}-0.074^{* * *} \\
(0.0022)\end{array}$ & $\begin{array}{r}-0.026^{* * *} \\
(0.0019)\end{array}$ & $\begin{array}{r}-0.018^{* * *} \\
(0.0018)\end{array}$ \\
\hline$R^{2}$ & 0.257 & & 0.284 & \\
\hline Pseudo $R^{2}$ & & 0.260 & & 0.297 \\
\hline Firm FE & yes & yes & yes & yes \\
\hline Time*2dig-Sector FE & yes & yes & yes & yes \\
\hline \multirow[t]{2}{*}{ Observations } & 279233 & 277425 & 283123 & 281267 \\
\hline & \multicolumn{4}{|c|}{ Panel B: Services } \\
\hline Conditions $_{t+1, t+6}$ & $\begin{array}{c}0.12^{* * *} \\
(0.0024)\end{array}$ & $\begin{array}{c}0.11^{* * *} \\
(0.0026)\end{array}$ & $\begin{array}{c}0.15^{* * *} \\
(0.0021)\end{array}$ & $\begin{array}{c}0.18^{* * *} \\
(0.0032)\end{array}$ \\
\hline Conditions $_{t, t-5}$ & $\begin{array}{c}-0.098^{* * *} \\
(0.0024)\end{array}$ & $\begin{array}{r}-0.088^{* * *} \\
(0.0025)\end{array}$ & $\begin{array}{c}-0.020^{* * *} \\
(0.0021)\end{array}$ & $\begin{array}{c}-0.032^{\text {*** }} \\
(0.002)\end{array}$ \\
\hline$R^{2}$ & 0.317 & & 0.300 & \\
\hline Pseudo $R^{2}$ & & 0.289 & & 0.320 \\
\hline Firm FE & yes & yes & yes & yes \\
\hline Time*2dig-Sector FE & yes & yes & yes & yes \\
\hline \multirow[t]{2}{*}{ Observations } & 245324 & 241954 & 219556 & 212997 \\
\hline & \multicolumn{4}{|c|}{ Panel C: Retail and Wholesale } \\
\hline Conditions $_{t+1, t+6}$ & $\begin{array}{c}0.14^{* * *} \\
(0.0028)\end{array}$ & $\begin{array}{c}0.14^{* * *} \\
(0.0039)\end{array}$ & $\begin{array}{c}0.16^{* * *} \\
(0.0027)\end{array}$ & $\begin{array}{c}0.16^{* * *} \\
(0.0042)\end{array}$ \\
\hline Conditions $_{t, t-5}$ & $\begin{array}{l}0.073^{* * *} \\
(0.0028)\end{array}$ & $\begin{array}{l}0.071^{* * *} \\
(0.0031)\end{array}$ & $\begin{array}{c}0.15^{* * *} \\
(0.0027)\end{array}$ & $\begin{array}{c}0.15^{* * *} \\
(0.0040)\end{array}$ \\
\hline$R^{2}$ & 0.306 & & 0.358 & \\
\hline Pseudo $R^{2}$ & & 0.307 & & 0.355 \\
\hline Firm FE & yes & yes & yes & yes \\
\hline Time*2dig-Sector FE & yes & yes & yes & yes \\
\hline Observations & 132551 & 132401 & 148113 & 147972 \\
\hline
\end{tabular}

Notes: This table reports the results of estimating a variant of the main specification from Column (5) of Table 2 for binarized versions of the discrete data on expectations. In Columns (1) and (2), the dependent variable equals one if Expectations ${ }_{t}^{+6 m}=1$ and zero if Expectations ${ }_{t}^{+6 m} \in\{-1,0\}$. In Columns (3) and (4), the dependent variable equals one if Expectations $t_{t}^{+6 m} \in\{0,1\}$ and zero if Expectations ${ }_{t}^{+6 m}=-1$. Columns (1) and (3) report the coefficient estimates obtained via OLS - as in the main text - with the binarized dependent variable. Columns (2) and (4) report the average partial effects estimated via the fixed effects logit model proposed by Fernández-Val and Weidner (2016), who suggest an analytical correction for the bias caused by the incidental parameters problem. "Pseudo $R^{2}$ " is the pseudo $R^{2}$ for discrete outcome models developed by McFadden (1973). All independent variables are defined as described in Table 2. The standard errors (in parentheses) of the OLS estimates are two-way clustered at the levels of firms and dates. The standard errors of the logit estimates are calculated as defined by Fernández-Val and Weidner (2016). Level of significance: ${ }^{*} p<0.10,{ }^{* *} p<0.05,{ }^{* * *} p<0.01$. 
Table 10: Panel Regressions: Robustness Checks-Fixed Effects, Attrition, and Normal Current Conditions

\begin{tabular}{|c|c|c|c|c|c|c|c|}
\hline & \multicolumn{7}{|c|}{ Expected Business Conditions for the Next 6 Months } \\
\hline & \multicolumn{7}{|c|}{ Panel A: Manufacturing } \\
\hline & (1) & $(2)$ & $(3)$ & (4) & $(5)$ & $(6)$ & (7) \\
\hline Conditions $_{t+1, t+6}$ & $\begin{array}{l}0.29^{* * *} \\
(0.0067)\end{array}$ & $\begin{array}{l}0.30^{* * * *} \\
(0.0070)\end{array}$ & $\begin{array}{l}0.28^{* * * *} \\
(0.0065)\end{array}$ & $\begin{array}{l}0.29^{* * * *} \\
(0.0065)\end{array}$ & $\begin{array}{l}0.29^{* * *} \\
(0.0067)\end{array}$ & $\begin{array}{l}0.29^{* * *} \\
(0.0070)\end{array}$ & $\begin{array}{l}0.27^{* * *} \\
(0.0080)\end{array}$ \\
\hline Conditions $_{t, t-5}$ & $\begin{array}{c}-0.098^{* * *} \\
(0.0091)\end{array}$ & $\begin{array}{l}-0.11^{* * *} \\
(0.0098)\end{array}$ & $\begin{array}{c}-0.085^{* * *} \\
(0.0085)\end{array}$ & $\begin{array}{c}-0.096^{* * *} \\
(0.0090)\end{array}$ & $\begin{array}{c}-0.099^{* * *} \\
(0.0091)\end{array}$ & $\begin{array}{l}-0.11^{* * *} \\
(0.0097)\end{array}$ & $\begin{array}{c}-0.20^{* * *} \\
(0.010)\end{array}$ \\
\hline$R^{2}$ & 0.329 & 0.318 & 0.351 & 0.335 & 0.327 & 0.333 & 0.323 \\
\hline Adjusted $R^{2}$ & 0.313 & 0.308 & 0.319 & 0.315 & 0.312 & 0.316 & 0.292 \\
\hline \multirow[t]{2}{*}{ Observations } & 331893 & 334467 & 331531 & 331893 & 329306 & 282368 & 163031 \\
\hline & \multicolumn{7}{|c|}{ Panel B: Services } \\
\hline Conditions $_{t+1, t+6}$ & $\begin{array}{l}0.25^{* * *} \\
(0.0086)\end{array}$ & $\begin{array}{l}0.26^{* * *} \\
(0.0088)\end{array}$ & $\begin{array}{l}0.24^{* * *} \\
(0.0084)\end{array}$ & $\begin{array}{l}0.25^{* * *} \\
(0.0084)\end{array}$ & $\begin{array}{l}0.25^{* * *} \\
(0.0086)\end{array}$ & $\begin{array}{l}0.25^{* * *} \\
(0.0093)\end{array}$ & $\begin{array}{l}0.25^{* * *} \\
(0.0090)\end{array}$ \\
\hline Conditions $_{t, t-5}$ & $\begin{array}{l}-0.11^{* * *} \\
(0.0079)\end{array}$ & $\begin{array}{l}-0.12^{* * *} \\
(0.0081)\end{array}$ & $\begin{array}{l}-0.10^{* * *} \\
(0.0076)\end{array}$ & $\begin{array}{l}-0.11^{* * *} \\
(0.0079)\end{array}$ & $\begin{array}{l}-0.11^{* * *} \\
(0.0079)\end{array}$ & $\begin{array}{l}-0.12^{* * *} \\
(0.0085)\end{array}$ & $\begin{array}{c}-0.17^{* * *} \\
(0.010)\end{array}$ \\
\hline$R^{2}$ & 0.368 & 0.356 & 0.384 & 0.372 & 0.365 & 0.370 & 0.360 \\
\hline Adjusted $R^{2}$ & 0.350 & 0.344 & 0.357 & 0.351 & 0.349 & 0.352 & 0.324 \\
\hline \multirow[t]{2}{*}{ Observations } & 303534 & 303936 & 303087 & 303401 & 300484 & 255611 & 136123 \\
\hline & \multicolumn{7}{|c|}{ Panel C: Retail and Wholesale } \\
\hline Conditions $_{t+1, t+6}$ & $\begin{array}{l}0.29^{* * *} \\
(0.0079)\end{array}$ & $\begin{array}{l}0.29^{* * *} \\
(0.0081)\end{array}$ & $\begin{array}{l}0.28^{* * *} \\
(0.0078)\end{array}$ & $\begin{array}{l}0.28^{* * *} \\
(0.0079)\end{array}$ & $\begin{array}{l}0.29^{* * *} \\
(0.0080)\end{array}$ & $\begin{array}{l}0.29^{* * *} \\
(0.0087)\end{array}$ & $\begin{array}{l}0.24^{* * *} \\
(0.0088)\end{array}$ \\
\hline Conditions $_{t, t-5}$ & $\begin{array}{l}0.21^{* * *} \\
(0.011)\end{array}$ & $\begin{array}{l}0.20^{* * *} \\
(0.012)\end{array}$ & $\begin{array}{l}0.21^{* * *} \\
(0.011)\end{array}$ & $\begin{array}{l}0.21^{* * *} \\
(0.011)\end{array}$ & $\begin{array}{l}0.21^{* * *} \\
(0.011)\end{array}$ & $\begin{array}{l}0.20^{* * *} \\
(0.012)\end{array}$ & $\begin{array}{c}0.035^{* * *} \\
(0.012)\end{array}$ \\
\hline$R^{2}$ & 0.436 & 0.433 & 0.444 & 0.443 & 0.434 & 0.436 & 0.321 \\
\hline Adjusted $R^{2}$ & 0.426 & 0.423 & 0.429 & 0.426 & 0.424 & 0.425 & 0.296 \\
\hline Observations & 180115 & 180339 & 180115 & 180115 & 178264 & 150254 & 88501 \\
\hline Firm FE & yes & yes & yes & yes & yes & yes & yes \\
\hline Time FE & no & yes & no & no & no & no & no \\
\hline Time*2dig-Sector FE & yes & no & no & yes & yes & yes & yes \\
\hline Time*3dig-Sector FE & no & no & yes & no & no & no & no \\
\hline Time*State FE & no & no & no & yes & no & no & no \\
\hline Firm in Sample for at Least 24 Months & no & no & no & no & yes & no & no \\
\hline Firm in Sample for at Least 1 More Year & no & no & no & no & no & yes & no \\
\hline Conditional on Normal Conditions in $t$ & no & no & no & no & no & no & yes \\
\hline
\end{tabular}

Notes: Conditions ${ }_{t+1, t+6}$ is the mean of the future realized business conditions in the following six months, which is the proxy for disaggregate information. Conditions $s_{t, t-5}$ is defined accordingly. "Time FE" are aggregate time fixed effects, "Time*2dig-Sector FE" are time fixed effects at the two-digit industry level, "Time*3dig-Sector FE" are time fixed effects at the three-digit industry level, and "Time*State FE" are time fixed effect at the level of the German states. The sample in Column (7) consists only of those firms that currently report normal business conditions, that is those firms for which Conditions $t_{t}=0$. Standard errors are two-way clustered at the levels of firms and dates. Level of significance: ${ }^{*} p<0.10,{ }^{* *} p<0.05$, *** $p<0.01$. 


\section{Column (4).}

The results also remain remarkably stable when we restrict the sample of firms to control for attrition. Neither restricting firms to be in the sample for at least two years in Column (5) nor dropping all observations of firms within one year of the last firm-specific observation in Column (6) alters the coefficient of interest.

Moreover, we rule out the possibility that firms at the extremes of the distribution of current conditions drive our results. Specifically, one concern could be that firms with unusual good or bad business conditions can expect these conditions to continue to be good or bad in the future with high confidence, and are thus very well informed about their future. Such a mechanism could generate our results, even if all other firms possess no information about their future disaggregate conditions. To deal with this concern, Column (7) of Table 10 estimates the main empirical model (4) only for those firms that currently report normal conditions. The comparison of the estimates for this restricted sample of firms to the benchmark results in the first column shows that the effect of disaggregate information on expectations is independent of whether firms currently deal with business as usual or face particularly good/bad business conditions.

Table 11 verifies that the benchmark results in Column (1) are unaffected by changing the vector of covariates. In Column (2), we alter the industry definition underlying the time fixed effects from the German industry classification of 2003 ( WZ 03), which we use throughout the paper, to the more recent German industry classification of 2008 ( $W Z$ 08). While this requires additional adjustments of the industry codes in the data of the IBS, doing so leaves the results completely unchanged. In Columns (3) and (4), we directly control for aggregate industry conditions by means of aggregate revenues. To this end, we generate a measure of detrended revenues at the two-digit industry level by computing the log deviation of the monthly revenue data (that is publicly available from the German statistical office for the manufacturing and retail/wholesale sectors) to the industry-specific trend in revenue. ${ }^{33}$ Column (3) then adds current (detrended) industry revenues as an additional covariate, while Column (4) includes average future revenues during the expectation window of six months. Note that Columns (3) and (4) do not include time fixed effects, as these are perfectly collinear to the industry-specific revenue data. Unsurprisingly, the coefficients of future realized business conditions in Columns (3) and (4) increase, because the industry-specific revenues only partially capture the industry-specific variation in business conditions. Note also that, as expected, the association between current revenues and expectations is not statistically significant, while the association between future industry-specific revenue levels and expectations is strong. Column (5) accounts for the possibility that firms extrapolate from past expectations when forming their current expectations by controlling for the expectations reported six months ago; these expectations cover an expectation window of the past six months (including the current month). Even though the association between past and current expectations is statistically significant, the association is economically small and does not alter the remaining coefficient estimates or the goodness of fit

\footnotetext{
${ }^{33}$ Following Ravn and Uhlig (2002), the monthly revenue data are detrended using a HP filter with smoothing parameter 129'600.
} 
Table 11: Panel Regressions: Robustness Checks-Additional Controls

\begin{tabular}{|c|c|c|c|c|c|c|c|}
\hline & \multicolumn{7}{|c|}{ Expected Business Conditions for the Next 6 Months } \\
\hline & \multicolumn{7}{|c|}{ Panel A: Manufacturing } \\
\hline Conditions $_{t+1, t+6}$ & $\begin{array}{l}0.29^{* * *} \\
(0.0067)\end{array}$ & $\begin{array}{l}0.28^{* * *} \\
(0.0065)\end{array}$ & $\begin{array}{l}0.39^{* * *} \\
(0.018)\end{array}$ & $\begin{array}{l}0.36^{* * *} \\
(0.012)\end{array}$ & $\begin{array}{l}0.29^{* * *} \\
(0.0068)\end{array}$ & $\begin{array}{l}0.21^{* * *} \\
(0.0073)\end{array}$ & $\begin{array}{c}0.24^{* * *} \\
(0.0068)\end{array}$ \\
\hline Conditions $_{t, t-5}$ & $\begin{array}{c}-0.098^{* * *} \\
(0.0091)\end{array}$ & $\begin{array}{c}-0.085^{* * *} \\
(0.0086)\end{array}$ & $\begin{array}{c}-0.15^{* * *} \\
(0.013)\end{array}$ & $\begin{array}{c}-0.17^{* * *} \\
(0.015)\end{array}$ & $\begin{array}{l}-0.12^{* * *} \\
(0.0094)\end{array}$ & & \\
\hline $\log \left(\right.$ Revenues $\left._{t}\right)$ & & & $\begin{array}{l}0.015 \\
(0.12)\end{array}$ & & & & \\
\hline $\log \left(\right.$ Revenues $\left._{t+1, t+6}\right)$ & & & & $\begin{array}{c}0.65^{* * *} \\
(0.14)\end{array}$ & & & \\
\hline Expectations $_{t-6}^{+6}$ & & & & & $\begin{array}{l}0.060^{* * *} \\
(0.0057)\end{array}$ & & \\
\hline Conditionst & & & & & & $\begin{array}{l}0.044^{* * *} \\
(0.0067)\end{array}$ & $\begin{array}{c}0.11^{* * *} \\
(0.0058)\end{array}$ \\
\hline Conditions $_{t-1, t-5}$ & & & & & & & $\begin{array}{c}-0.17^{* * *} \\
(0.0079)\end{array}$ \\
\hline$R^{2}$ & 0.329 & 0.350 & 0.285 & 0.289 & 0.332 & 0.327 & 0.335 \\
\hline Adjusted $R^{2}$ & 0.313 & 0.318 & 0.274 & 0.278 & 0.315 & 0.311 & 0.319 \\
\hline \multirow[t]{2}{*}{ Observations } & 331893 & 331742 & 331893 & 331893 & 311016 & 331893 & 328532 \\
\hline & \multicolumn{7}{|c|}{ Panel B: Services } \\
\hline Conditions $_{t+1, t+6}$ & $\begin{array}{l}0.25^{* * *} \\
(0.0086)\end{array}$ & $\begin{array}{l}0.24^{* * *} \\
(0.0082)\end{array}$ & & & $\begin{array}{l}0.25^{* * *} \\
(0.0089)\end{array}$ & $\begin{array}{l}0.21^{* * *} \\
(0.0085)\end{array}$ & $\begin{array}{l}0.23^{* * *} \\
(0.0083)\end{array}$ \\
\hline Conditions $t, t-5$ & $\begin{array}{l}-0.11^{* * *} \\
(0.0079)\end{array}$ & $\begin{array}{l}-0.10^{* * *} \\
(0.0077)\end{array}$ & & & $\begin{array}{l}-0.13^{* * *} \\
(0.0080)\end{array}$ & & \\
\hline Expectations $_{t-6}^{+6}$ & & & & & $\begin{array}{l}0.025^{* * *} \\
(0.0060)\end{array}$ & & \\
\hline Conditions $_{t}$ & & & & & & $\begin{array}{l}-0.014^{* *} \\
(0.0060)\end{array}$ & $\begin{array}{c}0.026^{* * *} \\
(0.0063)\end{array}$ \\
\hline Conditions $_{t-1, t-5}$ & & & & & & & $\begin{array}{l}-0.13^{* * *} \\
(0.0073)\end{array}$ \\
\hline$R^{2}$ & 0.368 & 0.390 & & & 0.374 & 0.364 & 0.369 \\
\hline Adjusted $R^{2}$ & 0.350 & 0.358 & & & 0.356 & 0.347 & 0.352 \\
\hline \multirow[t]{2}{*}{ Observations } & 303534 & 302225 & & & 262480 & 303534 & 296420 \\
\hline & \multicolumn{7}{|c|}{ Panel C: Retail and Wholesale } \\
\hline Conditions $_{t+1, t+6}$ & $\begin{array}{l}0.29^{* * *} \\
(0.0079)\end{array}$ & $\begin{array}{l}0.28^{* * *} \\
(0.0078)\end{array}$ & $\begin{array}{l}0.33^{* * *} \\
(0.011)\end{array}$ & $\begin{array}{l}0.32^{* * *} \\
(0.0098)\end{array}$ & $\begin{array}{l}0.28^{* * *} \\
(0.0082)\end{array}$ & $\begin{array}{l}0.22^{* * *} \\
(0.0074)\end{array}$ & $\begin{array}{l}0.21^{* * *} \\
(0.0073)\end{array}$ \\
\hline Conditions $_{t, t-5}$ & $\begin{array}{l}0.21^{* * *} \\
(0.011)\end{array}$ & $\begin{array}{l}0.21^{* * *} \\
(0.011)\end{array}$ & $\begin{array}{l}0.21^{* * *} \\
(0.012)\end{array}$ & $\begin{array}{l}0.20^{* * *} \\
(0.013)\end{array}$ & $\begin{array}{l}0.18^{* * *} \\
(0.012)\end{array}$ & & \\
\hline $\log ($ Revenues $t)$ & & & $\begin{array}{l}0.093 \\
(0.14)\end{array}$ & & & & \\
\hline $\log \left(\right.$ Revenues $\left._{t+1, t+6}\right)$ & & & & $\begin{array}{c}0.84^{* * *} \\
(0.21)\end{array}$ & & & \\
\hline Expectations $_{t-6}^{+6}$ & & & & & $\begin{array}{l}0.065^{* * *} \\
(0.0061)\end{array}$ & & \\
\hline Conditions $_{t}$ & & & & & & $\begin{array}{c}0.25^{* * *} \\
(0.0069)\end{array}$ & $\begin{array}{c}0.25^{* * *} \\
(0.0065)\end{array}$ \\
\hline Conditions $_{t-1, t-5}$ & & & & & & & $\begin{array}{c}0.016^{*} \\
(0.0089)\end{array}$ \\
\hline$R^{2}$ & 0.436 & 0.446 & 0.414 & 0.415 & 0.438 & 0.460 & 0.460 \\
\hline Adjusted $R^{2}$ & 0.426 & 0.430 & 0.404 & 0.405 & 0.428 & 0.450 & 0.450 \\
\hline Observations & 180115 & 180109 & 180115 & 180115 & 164299 & 180115 & 177508 \\
\hline Firm FE & yes & yes & yes & yes & yes & yes & yes \\
\hline Time*2dig-Sector FE & yes & no & no & no & yes & yes & yes \\
\hline Time*2dig-Sector FE (WZ08) & no & yes & no & no & no & no & no \\
\hline
\end{tabular}

Notes: Conditions $s_{t+1, t+6}$, Conditions ${ }_{t, t-5}$, Conditions ${ }_{t}$, and Conditions C $_{t+1, t-5}$ are defined as in the remainder of the paper. $\log \left(\right.$ Revenues $\left._{t}\right)$ is the log deviation of monthly revenues at the two-digit industry level from its HP-filtered trend; $\log \left(\right.$ Revenues $\left._{t+1, t+6}\right)$ is its average between $t+1$ and $t+6$. The revenue data are unavailable for services. Expectations $_{t-6}^{+6 m}$ are the expectations as of $t-6$. "Time*2dig-Sector FE" and "Time*2dig-Sector FE (WZ08)" are time fixed effects at the two-digit industries levels according to the German industry classifications of 2003 and 2008 , respectively. Standard errors are two-way clustered at the levels of firms and dates. Level of significance: $* p<0.10$, ** $p<0.05, * * * p<0.01$. 
substantially. In Columns (6) and (7), we separately control for current realized conditions, with and without past conditions. This also has little impact on the parameter estimates of interest.

\section{Robustness Checks for Section 5: The Effect of Information on Expectation Formation}

\section{C.1. Additional Tables and Figures}

Figure 5: The Effect of the VAT Increase in 2007 on Other Retail Firms

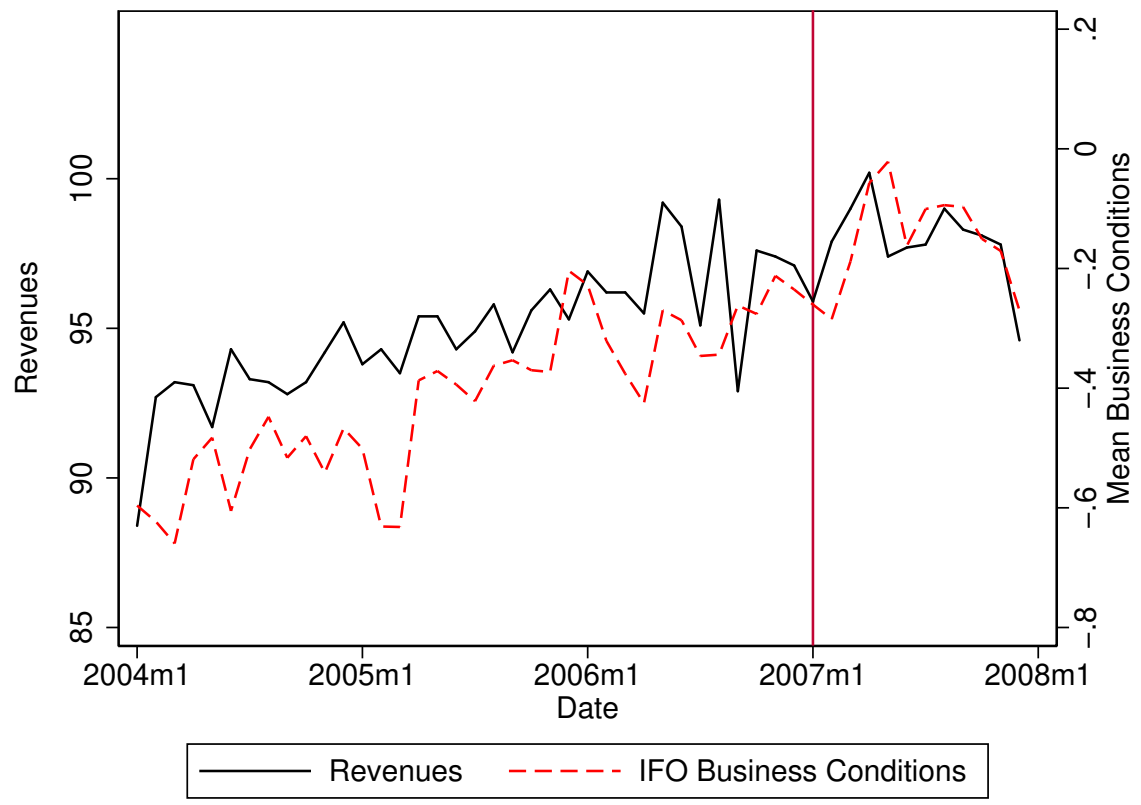

Notes: This figure plots the time series of revenues in a subset of sectors "not treated" by the VAT change (black line) against the reported business conditions of the control firms in the IBS. The subset of control firms comprises of retailers within the WZ 08 group "47.7 Indoor retail trade with other goods" which contains clothes, shoes, leather goods, pharmaceuticals, medical/orthopedical/cosmetic goods, flowers/plants/fertilizer/animals, watches/luxury goods, glasses, photographic/optic goods, art/paintings, antiques, used goods, etc. The vertical red line corresponds to the date of the VAT increase (January 2007). 
Table 12: Retail Firms' Expectations and Disaggregate Information

\begin{tabular}{lcccccc}
\hline \multicolumn{5}{c}{ Expected Business Conditions for the Next 6 Months } \\
\hline Conditions $_{t+1, t+6}$ & $0.29^{* * *}$ & $0.26^{* * *}$ & $0.26^{* * *}$ & & & \\
& $(0.017)$ & $(0.021)$ & $(0.019)$ & & & \\
Conditions $_{t, t-5}$ & $0.25^{* * *}$ & $0.24^{* * *}$ & $0.25^{* * *}$ & & & \\
& $(0.019)$ & $(0.025)$ & $(0.022)$ & & & \\
Conditions $_{t+4, t+6}$ & & & & $0.10^{* * *}$ & $0.078^{* * *}$ & $0.072^{* * *}$ \\
& & & & $(0.015)$ & $(0.015)$ & $(0.015)$ \\
Conditions $_{t+1, t+3}$ & & & & $0.18^{* * *}$ & $0.16^{* * *}$ & $0.16^{* * *}$ \\
& & & & $(0.011)$ & $(0.012)$ & $(0.011)$ \\
Conditions $_{t, t-2}$ & & & & $0.25^{* * *}$ & $0.23^{* * *}$ & $0.24^{* * *}$ \\
& & & & $(0.019)$ & $(0.021)$ & $(0.017)$ \\
Conditions $_{t-3, t-5}$ & & & & 0.0037 & -0.0047 & -0.0088 \\
& & & & $(0.014)$ & $(0.013)$ & $(0.013)$ \\
\hline$R^{2}$ & 0.205 & 0.481 & 0.491 & 0.214 & 0.490 & 0.501 \\
Adjusted $R^{2}$ & 0.205 & 0.462 & 0.472 & 0.214 & 0.471 & 0.482 \\
Firm FE & no & yes & yes & no & yes & yes \\
Time FE & no & no & yes & no & no & yes \\
Observations & 26711 & 26688 & 26688 & 24830 & 24798 & 24798 \\
\hline
\end{tabular}

Notes: Conditions $t_{t+1, t+6}$ is the mean of the future reported business conditions in the following six months. Conditions $_{t+4, t+6}$, Conditions $t_{t+1, t+3}$, Conditions $t_{t, t-5}$, Conditions C $_{t, t-2}$, and Conditions $t-3, t-5$ are defined accordingly. The sample includes all retail firms in the IBS between January 2004 and December 2007 that respond to the survey between $t-5$ and $t+6$. Standard errors are two-way clustered at the levels of firms and dates. Level of significance: ${ }^{*} p<0.10,{ }^{* *} p<0.05,{ }^{* * *} p<0.01$.

\section{C.2. Robustness}

This section performs a series of robustness checks for the difference-in-differences estimates in Table 6 and shows that the results are robust to alternative specifications of the treatment period, alternative specifications of the control group, dealing with sample attrition, the coverage window of the data set, and the specification of the vector of fixed effects. Row (1) of Table 13 displays the estimates of the difference-in-differences coefficients collected in the vector $\boldsymbol{\delta}$ of the baseline specification; the remaining rows summarize the robustness checks, with each row representing one alternative specification.

Panel A shows that the results are robust to alternative definitions of the treatment period. In the baseline specification, we have defined the treatment period as the months between April 2006 and February 2007, as firms' expectation windows during these months cover at least four months of the anticipation effects in demand between July 2006 and June 2007 depicted in Figure 3. However, the dates during which the demand effects of the VAT increase should be expected has not been well-defined ex ante, so that the choice of the treatment period is somewhat arbitrary. We hence confirm that alternative definitions of the treatment period do not alter the results. First, we consider the alternative definition of the treatment period between June and December 2006, that symmetrically shortens the treatment period by two months. As a consequence, the six month expectation windows within the treatment period are more narrowly concentrated around the VAT 
Table 13: The Effect of More Precise Information on Expectations: Robustness Checks

\begin{tabular}{lcccccc}
\hline & \multicolumn{4}{c}{ Difference-in-Differences Coefficients } & & \\
\cline { 2 - 5 } & $\operatorname{Cond}_{t+4, t+6}$ & $\operatorname{Cond}_{t+1, t+3}$ & $\operatorname{Cond}_{t, t-2}$ & Cond $_{t-3, t-5}$ & Obs. Adj. $R^{2}$ \\
\hline (1) Baseline Specification & $\begin{array}{c}0.15^{* * *} \\
(0.059)\end{array}$ & $\begin{array}{c}0.018 \\
(0.044)\end{array}$ & $\begin{array}{c}-0.14^{* * *} \\
(0.052)\end{array}$ & $\begin{array}{c}-0.016 \\
(0.045)\end{array}$ & 24798 & 0.502 \\
\hline
\end{tabular}

Panel A: Robustness to the Specification of the Treatment Period

$\mathbb{1}\left(\operatorname{VAT}_{t}\right)=1$ if

(2) $t \in(2006 m 6,2006 m 12)$

\begin{tabular}{cccccc}
$0.17^{* * *}$ & 0.056 & $-0.14^{* *}$ & -0.026 & 24798 & 0.503 \\
$(0.064)$ & $(0.051)$ & $(0.067)$ & $(0.058)$ & & \\
$0.14^{* *}$ & 0.057 & $-0.14^{* *}$ & 0.00091 & 24798 & 0.503 \\
$(0.064)$ & $(0.044)$ & $(0.057)$ & $(0.051)$ & & \\
\hline
\end{tabular}

Panel B: Robustness to the Choice of the Control Group

(4) Control Group: Retail \& Wholesale

\begin{tabular}{lccccc}
$0.15^{* * *}$ & 0.022 & $-0.12^{* *}$ & -0.011 & 50923 & 0.494 \\
$(0.045)$ & $(0.041)$ & $(0.047)$ & $(0.033)$ & & \\
\hline
\end{tabular}

Panel C: Restrictions on Minimum Duration in Sample (Attrition)

(5) Firm in Sample for at Least 24 Months

(6) Firms in Sample at Least 2006m4-2007m2

(7) Firms in Sample at Least 2005m6-2007m12

\begin{tabular}{lccccc}
$0.18^{* * *}$ & 0.033 & $-0.19^{* * *}$ & -0.0013 & 21270 & 0.493 \\
$(0.055)$ & $(0.048)$ & $(0.052)$ & $(0.043)$ & & \\
$0.17^{* * *}$ & 0.018 & $-0.16^{* * *}$ & -0.015 & 19990 & 0.493 \\
$(0.054)$ & $(0.047)$ & $(0.051)$ & $(0.044)$ & & \\
$0.15^{* * *}$ & 0.031 & $-0.17^{* * *}$ & 0.014 & 17923 & 0.491 \\
$(0.055)$ & $(0.049)$ & $(0.054)$ & $(0.042)$ & & \\
\hline
\end{tabular}

Panel D: Robustness to the Time Window Covered by the Dataset

(8) Dataset Covers 2005m3-2007m12

\begin{abstract}
$0.16^{* *}$
(0.063)
\end{abstract}

0.020
$(0.045)$

$-0.12^{* *}$

$(0.055)$

$-0.050$

$(0.046)$

$18056 \quad 0.510$

Panel E: Robustness to the Specification of Fixed Effects

\begin{tabular}{lcccccc} 
(9) FE: Firm only & $0.23^{* * *}$ & -0.0010 & $-0.17^{* * *}$ & -0.031 & 24798 & 0.493 \\
& $(0.072)$ & $(0.046)$ & $(0.057)$ & $(0.047)$ & & \\
(10) FE: Firm, Time*State & $0.14^{* *}$ & 0.022 & $-0.13^{* *}$ & -0.0082 & 24783 & 0.521 \\
& $(0.059)$ & $(0.044)$ & $(0.052)$ & $(0.048)$ & & \\
\hline
\end{tabular}

Notes: Each row of the table corresponds to the results of one robustness check and reports the respective estimate of the vector $\boldsymbol{\delta}$ in model (7), that is, the VAT-induced change in the coefficients of business conditions two quarters ahead (Conditions ${ }_{t+4, t+6}$ ), of business conditions one quarter ahead (Conditions ( $_{t+1, t+3}$ ) and of the current quarter's and the past quarter's conditions (Conditions ${ }_{t, t-2}$ and Conditions ${ }_{t-3, t-5}$, respectively). Each robustness specification alters one dimension of the baseline specification reported in Table 6: Panel A alters the definition of the treatment (VAT) period (baseline: April 2006-February 2007), Panel B alters the control group (baseline: all non-durable good retailers), Panel $\mathrm{C}$ restricts the minimum duration of firms in the sample (baseline: no restriction), Panel D alters the coverage window of the dataset (baseline: January 2004-December 2007), and Panel E alters the definition of the fixed effects (baseline: firm and time fixed effects). Standard errors are two-way clustered at the levels of firms and dates. Level of significance: ${ }^{*} p<0.10,{ }^{* *} p<0.05,{ }^{* * *} p<0.01$. 
increase in January 2007, so that firms should be more confident in expecting the VAT-induced demand effects. As displayed in Row (2) of Table 13, this leaves the results largely unchanged. If anything, firms appear to be even more forward looking during this more narrow treatment periodthe increase in the coefficient of Conditions ${ }_{i,(t+4, t+6)}$ is larger than for the baseline specificationpotentially reflecting the higher confidence regarding the occurence of the VAT-induced demand effects. Second, we define the treatment period in such a way that it stronger reflects the temporal asymmetry in the change in business conditions due to the VAT increase. Figure 3 shows that the upward movement in business conditions before the demand shock occurs mainly from September 2006 onwards, while the reversal lasts at least until June 2007. Accordingly, we estimate the DiD specification with the alternative definition of the treatment period as the time between June 2006 and April 2007. The results in Row (3) show that this has no effect on the results.

Panel B confirms that our results are robust to using the data from the entire retail/wholesale survey of the IBS instead of focusing on retail firms only. In our main specification, we exclude wholesale firms from the control group, as these firms potentially face different business conditions than retail firms. The results in Row (4) of Table 13 show, however, that the results do not depend on whether or not wholesale firms are dropped from the sample.

Panel C of Table 13 deals with the fact that the IBS panel is unbalanced and that firms enter and exit the sample. To test whether entry or exit of firms affects our results, we restrict the sample to firms that are observed "long enough." In Row (5), we only consider firms that are observed for at least 24 months. This ensures that the firm fixed effects are estimated with sufficient precision, and that there is within firm variation in business conditions and expectations over time for most firms. In Row (6) we require firms to be in the sample during the entire treatment period between April 2006 and February 2007, and in Row (7) we consider the subset of firms that are observed 10 months before and after the treatment in addition to the entire treatment period. These sample restrictions are designed to ensure that the results are not driven by firms entering or exiting the market due to (anticipation of) the VAT-increase. The results show that, if anything, firms that remain in the sample for longer time periods - potentially more "experienced" or established firms - become more forward looking in advent of the VAT-induced information shock than the firms in the baseline sample.

Panel D confirms that the results are robust with respect to the time period covered by the data set. In Section 5, we use data from the retail/wholesale survey of the IBS starting from January 2005 in order to ensure a pre-treatment period of sufficient length. In contrast, in Section 4 the first observation is in March 2005 due to the later introduction of the services survey of the IBS. Restricting the time window of the dataset to the time between March 2005 and December 2007 (before the onset of the Great Recession in 2008) leaves the treatment effects in response to the VAT-induced information shock virtually unchanged, even though doing so cuts the pre-treatment period in half.

In a last step, we estimate the treatment effects with different specifications of the vector of fixed effects in model (8). Row (9) of Table 13 show that the treatment effects are more pronounced if 
the firm fixed effects are excluded. The treatment effects are of roughly the same magnitude as the baseline results if we apply separate time fixed effects for each of the German states.

We conclude that all robustness checks confirm the main finding of Section 5 that firms "treated" by the VAT-induced increase in the quality of information about future business conditions become significantly more forward-looking once the time of the disaggregate demand shock enters their six month expectation window. Across all specifications, this finding is driven by the strong reduction of the extent to which expectations are informed by current conditions and the strong increase of the extent to which expectations reflect the more distant future business conditions two quarters ahead. 